\title{
Recent Advances in the Development of Antimicrobial and Antifouling Biocompatible Materials for Dental Applications
}

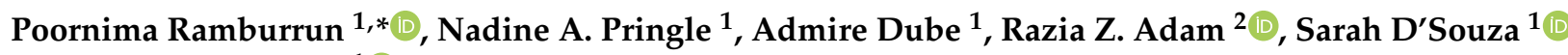 \\ and Marique Aucamp ${ }^{1}$ (D) \\ 1 School of Pharmacy, Faculty of Natural Sciences, University of the Western Cape, \\ Cape Town 7535, South Africa; 4078543@myuwc.ac.za (N.A.P.); adube@uwc.ac.za (A.D.); \\ sd'souza@uwc.ac.za (S.D.); maucamp@uwc.ac.za (M.A.) \\ 2 Department of Restorative Dentistry, Faculty of Dentistry, University of the Western Cape, \\ Cape Town 7505, South Africa; rzadam@uwc.ac.za \\ * Correspondence: pramburrun@uwc.ac.za; Tel.: +27-11-959-9255
}

Citation: Ramburrun, P.; Pringle, N.A.; Dube, A.; Adam, R.Z.; D'Souza, S.; Aucamp, M. Recent Advances in the Development of Antimicrobial and Antifouling Biocompatible Materials for Dental Applications. Materials 2021, 14, 3167.

https://doi.org/10.3390/ma14123167

Academic Editor: Javier Gil

Received: 30 April 2021

Accepted: 2 June 2021

Published: 9 June 2021

Publisher's Note: MDPI stays neutral with regard to jurisdictional claims in published maps and institutional affiliations.

Copyright: (c) 2021 by the authors. Licensee MDPI, Basel, Switzerland. This article is an open access article distributed under the terms and conditions of the Creative Commons Attribution (CC BY) license (https:/ / creativecommons.org/licenses/by/ $4.0 /)$.

\begin{abstract}
The risk of secondary bacterial infections resulting from dental procedures has driven the design of antimicrobial and antifouling dental materials to curb pathogenic microbial growth, biofilm formation and subsequent oral and dental diseases. Studies have investigated approaches based primarily on contact-killing or release-killing materials. These materials are designed for addition into dental resins, adhesives and fillings or as immobilized coatings on tooth surfaces, titanium implants and dental prosthetics. This review discusses the recent developments in the different classes of biomaterials for antimicrobial and antifouling dental applications: polymeric drug-releasing materials, polymeric and metallic nanoparticles, polymeric biocides and antimicrobial peptides. With modifications to improve cytotoxicity and mechanical properties, contact-killing and anti-adhesion materials show potential for incorporation into dental materials for long-term clinical use as opposed to short-lived antimicrobial release-based coatings. However, extended durations of biocompatibility testing, and adjustment of essential biomaterial features to enhance material longevity in the oral cavity require further investigations to confirm suitability and safety of these materials in the clinical setting. The continuous exposure of dental restorative and regenerative materials to pathogenic microbes necessitates the implementation of antimicrobial and antifouling materials to either replace antibiotics or improve its rational use, especially in the day and age of the ever-increasing problem of antimicrobial resistance.
\end{abstract}

Keywords: antimicrobial and antifouling materials; dental restorative materials; polymers; biofilms; periodontitis; recurrent caries

\section{Introduction}

According to the World Health Organization (WHO), oral diseases affect nearly 3.5 billion people worldwide [1]. The hard and soft tissue surfaces of the oral cavity provide the ideal environment for abundant microbial growth and biofilm formation (also known as dental plaque) [2]. With increased attraction of dental reconstructive and replacement procedures-microbial growth and biofilm formation has extended its territory to the surfaces of the artificial materials implemented in these restorative applications. The use of long-wear dental materials intensifies the clinical management of pathogenic microbes and increases the risk for oral disease such as dental caries, periodontitis, peri-implantitis, mucosal disease and oral cancer [3]. Tooth-loss, disfigurement, pain and difficulties in eating and speaking associated with inefficient oral hygiene ensuing oral disease cause significant psychological and social distress in afflicted patients [4].

Amid concerns over microbial resistance, there is a plea to develop novel antimicrobial compounds as well as to reduce unnecessary antibiotic dental prescriptions to prevent the emergence of resistant pathogens [5,6]. Antiseptic cavity cleaning solutions and oral 
rinses paired with aerated-water sprays and mechanical cleaning (professional and daily teeth-brushing with fluoridated products) are commonly used for chemical bacterial elimination and physical detachment of bacteria from the tooth and dental material surface, respectively [4,7]. Lack of regular oral hygiene, inadequately cleaned dental prosthesis and the continuous accumulation of bacteria makes it impossible to completely eliminate the microbial burden in the oral cavity.

It has been realized that restorative dental materials capable of bacterial growth inhibition and prevention of microleakage (between the tooth-material interface) is needed to prevent recurring infections, recurrent caries and failure of dental restorative procedures $[8,9]$. Such antimicrobial and antifouling materials either release components which kill microbes upon contact or interrupt and prevent microbial attachment and biofilm formation, respectively. This led to the development of the first commercial antimicrobial dental bonding resin system in 1994-the bactericidal 12-methacryloyloxydodecylpyridinium bromide (MDPB) monomer currently used in the product CLEARFIL SE Protect $[10,11]$. Since then, MDPB-immobilized resinous materials have been common in dental reconstructive and restorative procedures to curb the occurrence of secondary bacterial infections and subsequent oral diseases [12].

Antimicrobial and antifouling dental materials offer a promising role in the prevention of secondary caries, demineralization processes and implant failure occurring from biofilm formation on dental tissues and the dental materials utilized [12]. Transition to these materials may further ascribe to simpler daily maintenance of oral hygiene and longer wear resistance of dental materials. The advancement of antimicrobial and antifouling dental materials includes a variety of release-based and immobilization strategies comprising: (1) antibiotic and antiseptic compounds; (2) metal ions; (3) polymeric biocides and (4) antimicrobial peptides from a host of dental resins, adhesive systems, implant coatings and biodegradable polymeric drug delivery devices.

The challenge in developing antimicrobial and antifouling dental materials for clinical use lie in the pursuit of achieving the optimal features of biocompatibility, bioregeneration and rechargeability - without compromise on mechanical properties, surface properties and aesthetic appeal [13,14]. Additional essential features of antimicrobial and antifouling materials for dental applications are elaborated in Table 1.

This paper provides an overview of the emerging trends and developments in antimicrobial and antifouling biomaterials for various dental restorative, reconstructive and replacement strategies. Concerns persist surrounding the toxicity of leachable unreacted monomers from partially cured resin systems, despite their established antimicrobial efficiency. As such, cytocompatibility appeal is highlighted, where possible, in these developments as it is a pertinent property to approve any material for implantation or use in the human body, particularly the oral cavity. The types of microbial susceptibility and the challenges associated with restorative, prosthetic, endodontic and regenerative materials are also expressed.

Table 1. Essential features of antimicrobial and antifouling materials for dental applications.

\begin{tabular}{ll}
\hline Biomaterial Features and Requirements & \multicolumn{1}{c}{ Importance and Function } \\
\hline & (i) Surface hardness and toughness to resist indentation and \\
& fracture by masticatory forces or abrasive foods. \\
& (ii) Compressive, tensile and flexural strength to withstand \\
& multidirectional forces of mastication. \\
(iii) Resist long-term wear and tear to minimise maintenance & and replacement. \\
& (iv) Maintain structural integrity to support tissue regeneration.
\end{tabular}


Table 1. Cont.

Biomaterial Features and Requirements Importance and Function References

(i) Textural and tribological compatibility with mucous membranes, dentine and dental pulp, bone or enamel.

(ii) Minimal systemic and local cytotoxicity against dental tissue, gingiva and mucous membranes from corrosion or leaching of materials.

Biocompatibility and biomimicry

(iii) Bioinertness to avoid foreign body reactions, inflammation or systemic reactions.

(iv) Maintain native bone integrity to prevent peri-implantitis and bone resorption.

(v) Surface modification to enhance cellular activity, molecular signalling and tissue regeneration.

(vi) Optical properties comparative to native teeth for seamless aesthetic appeal.

Bioerosion and biocorrosion of long-term materials

- $\quad$ Prevent release of oligomers and monomers; pore formation and layer-by-layer corrosion (i) Minimise physical degradation by limiting fluid diffusion and absorption into the material leading to formation of a softened network.

(ii) Minimise chemical degradation via hydrolysis catalysed by salivary or bacterial enzymes; or acidic and alkaline foods and liquids.

(i) Maintenance and efficacy of antimicrobial or antifouling activity in short-term tissue regeneration scaffolds or long-term restorative materials.

(ii) Rechargeability of antimicrobial, antifouling or remineralising

Duration of antimicrobial or antifouling activity and rechargeability effects to minimise complete material replacement and maintain long-term efficacy (for example: calcium and phosphate ion-rechargeable dental composites).

(iii) Immobilisation strategies for enhanced stability and protection of antimicrobial and antifouling compounds against dilution and inactivation from salivary proteins and enzymes in coating materials.

(i) High surface energy encourages microbial adhesion.

(ii) Rough surface texture encourages cell adhesion of regenerating tissues via increased contact surface area but also encourages microbial adhesion.

Surface properties

(iii) Hydrophilic surfaces enhance cellular adhesion of regenerating tissues but prevents microbial adhesion.

(iv) Superhydrophobic surfaces prevent both microbial and cellular adhesion of regenerating tissues.

Bioregeneration

- $\quad$ Encourage guided tissue regeneration

- Enhance remineralization of hard tissues

- Control drug and bioactive delivery

- Tailor biodegradation rates

Fabrication, processing and handling requirements (i) Roughened or micro-patterned surface topography to assist with cellular adhesion at material-tissue interface.

(ii) Delivery of anti-inflammatory compounds, growth factors, stem cells or remineralizing composites to function as therapeutic and chemical cues to stimulate new tissue growth and enhance material-tissue interactions (i.e., osteointegration and osteoinduction).

(iii) Biodegradation to match rate of tissue regeneration to avoid occlusion or hindrances in tissue healing.

(i) Scalable fabrication methods for reproducibility and quality.

(ii) Ease of material workability upon bio-implantation.

(iii) Withstand thermal and chemical sterilization processes and $[27,28]$ packaging. 


\section{Microbial Susceptibility in Dental Materials}

Dental restorations and implants that are introduced into the oral cavity have the potential to alter the physiological, chemical and mechanical environment of the oral cavity, thereby creating new niches for various microorganisms [29]. Dental materials are thus vulnerable to aggressive bacterial attack once placed in the oral cavity [30]. The microbial susceptibility of dentures and other dental materials is primarily influenced by the topography and surface chemistry of the material. Dental caries or cavities are identified as the dominant chronic infectious disease within the oral cavity where the rate of dental cavity formation is estimated to be as high as $50-60 \%$ following restorative treatment. The primary cariogenic bacteria responsible for cavity formation include Streptococcus mutans, Lactobacilli spp., Actinomyces spp. and other anaerobic bacteria [31,32]. The adherence of such cariogenic bacteria to dental materials results in the biodegradation of these materials. Furthermore, cariogenic bacteria promote the development of secondary caries-one of the principal causes of glass-ionomer cement and composite resin restoration degradation and failure-as well as peri-implantitis [30,32]. Respiratory pathogens, such as Streptococcus pneumoniae, have also been shown to colonise dentures of the elderly population indicating that denture plaque may act as a reservoir for potential respiratory pathogens [33].

Likewise, dental materials are also prone to fungal contamination as fungi are effectively able to adhere to various resin, glass and metal surfaces. Fungal growth has been shown to degrade denture liners and subsequently cause tissue irritation. Individuals wearing dentures thus appear to be particularly susceptible to fungal infection as there is a strong correlation between the presence of Candida albicans and denture stomatitis [34,35]. The susceptibility of dental materials to viral infections appears less well studied, however, several viral species have been found in the oral cavity with human herpes viruses being the most common. Viruses are suspected to be involved in the development of various ulcers, tumours and infectious diseases in the oral cavity as well as periodontitis [36].

Bacteria, fungi and viruses seldom grow separately from one another in the oral cavity and instead tend to form consortiums that result in the formation of biofilms. A biofilm, such as dental plaque, is an aggregation of various microorganisms organised in thin layers and embedded in a self-produced matrix consisting of extracellular polymeric substances (EPS) which can form on natural dental tissues as well as the surface of various dental materials [29]. The formation of biofilms occurs through a multi-step process involving microbial attachment followed by biofilm maturation and biofilm dispersal, as depicted in Figure 1 [37]. Every surface within the oral cavity is covered by a pellicle of glycoproteins (naturally present in saliva) and it is to this layer of glycoproteins that microorganisms can adhere. During biofilm formation, Gram-positive bacterial species such as Streptococcus spp. and Actinomyces spp. are referred to as pioneer species as they are generally the first microorganisms to adhere to the dental pellicle. These species thus perform a crucial role in creating and sustaining conditions that enable other microorganisms to colonise and thrive on dental surfaces and materials. Their respiration process creates hypoxic conditions that make it conducive for the growth of various anaerobic species [38].

The role of oral biofilms in pathogenesis is dependent on the composition and the location of the biofilm. Biofilms containing microorganisms that produce acid at the toothrestoration margin may cause recurrent caries as well as pulp infections; biofilms persisting in the root canal system following root canal therapy may cause re-infection as well as persistent apical periodontitis. Biofilms growing on periodontal tissues and dental implants could result in periodontitis and peri-implantitis whereas biofilms on dentures are associated with malodour, aspiration pneumonia and various systemic conditions-particularly amongst the elderly and dependent [34,37]. Oral biofilms are difficult to remove as these communities of microorganisms act as a single unit within the EPS matrix which protects them from chemical treatments. Limited access to surfaces between the teeth and deep crevices on the tooth makes it difficult to expel these microbial colonies. This situation further complicates the clinical applications of dental materials due to the presence of pores, margins and fissures on both the material and tissue surfaces [29]. 


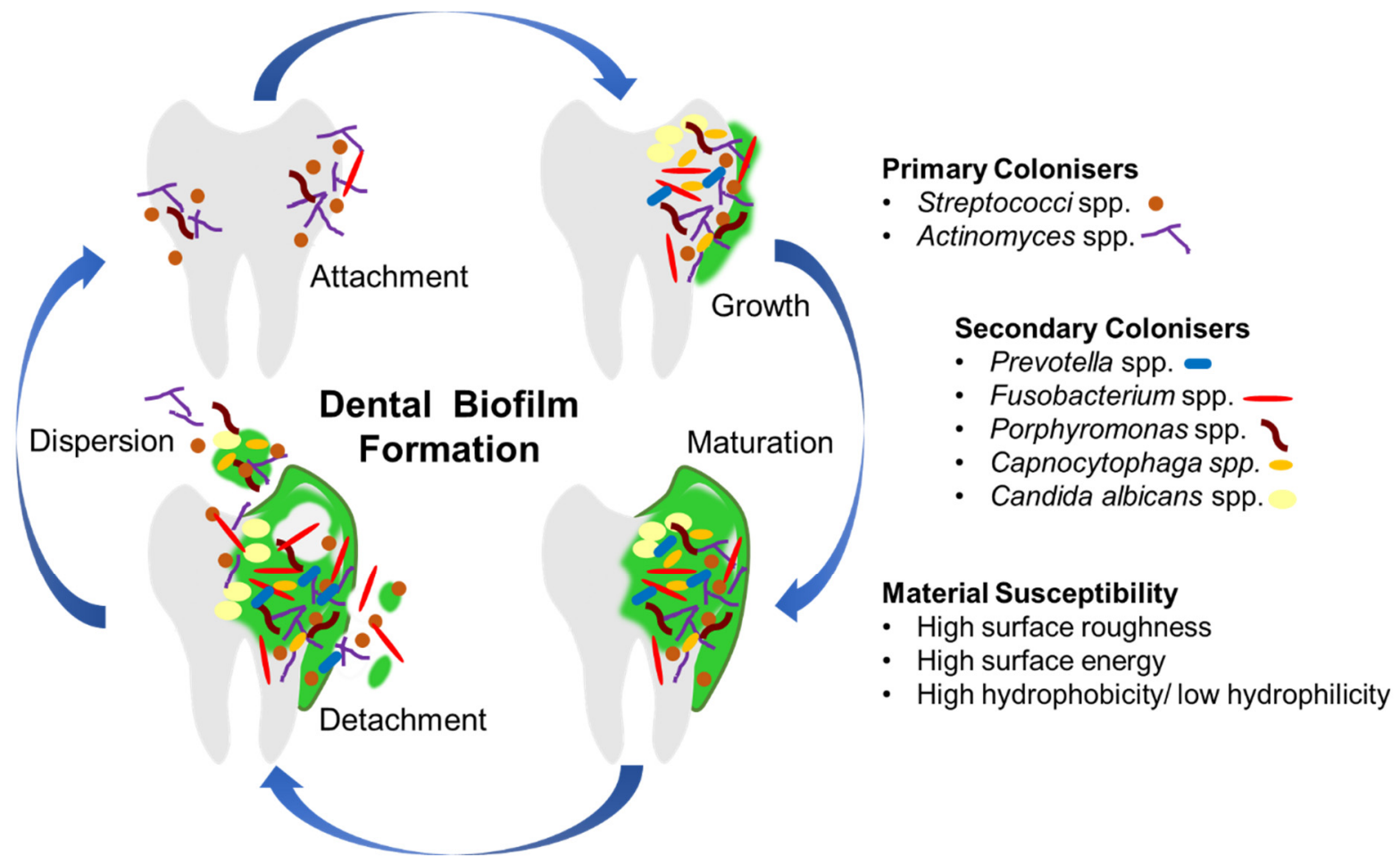

Figure 1. Schematic representation of primary dental microbes and biofilm formation.

\section{The Role of Antimicrobial and Antifouling Materials in Clinical} Dental Applications

3.1. Dental Luting Cements

Dental luting cements are used to connect indirect restorations permanently in the mouth (Figure 2a) by filling the void between the restoration-tooth interface to avoid dislodgement during mastication [39]. Failure of crowns and fixed partial dentures may be attributed to a loss of crown retention. Recurrent caries is also commonly implicated in the failure of fixed partial dentures. Dissolution of dental cements at the margins may result in marginal microleakage and the accumulation of cariogenic bacteria. Similarly, in orthodontics, the accumulation of cariogenic bacteria around the margins of fixed orthodontic apparatus results in enamel demineralisation and the appearance of white spot lesions which occur in $50 \%$ of patients [40].

(a)

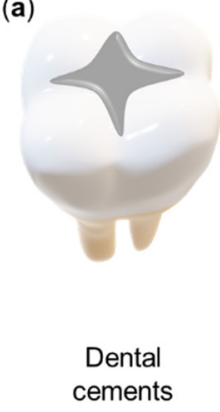

(b)

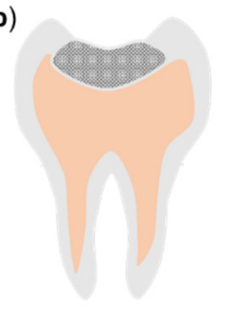

Dental adhesives and
direct restorative materials (c)

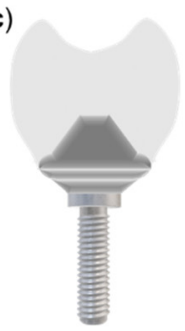

Prosthetic materials and dental implants (d)

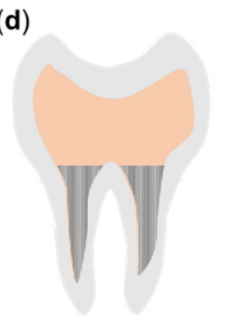

Endodontic and dental-filling materials

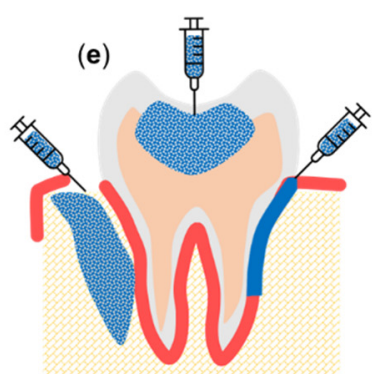

Regenerative and graft materials

Figure 2. Illustrations of dental material applications that require antimicrobial and antifouling properties: (a) dental cements; (b) dental adhesives and direct restorative materials; (c) prosthetic materials and dental implants; (d) endodontic and dental-filling materials; (e) regenerative and graft materials. 
In addition to high compressive strength and stiffness, luting cements should be translucent, biocompatible and anticariogenic [41]. The introduction of antimicrobial and antifouling dental cements may reduce the failure of fixed restorations by eliminating the bacterial colonies that remain underneath the restoration and preventing microleakage between the cement-tissue interface [42]. To confer antimicrobial activity, most studies investigate the incorporation of metallic nanoparticles of silver, zinc oxide or titanium dioxide into glass ionomer luting cements [42-44] or copper-containing glass ionomer and zinc oxide phosphate cements [45,46]. Other methods have explored the inclusion of chlorhexidine and propolis [47] as well as contact killing cationic quaternary ammonium compounds (QACs) in glass ionomer cements [48].

\subsection{Dental Adhesives and Direct Restorative Materials}

Dental composite resin materials (Figure $2 b$ ) are commonly used to restore teeth. However, these tend to accumulate more biofilm compared to other dental materials and experience faster degradation due to microbial growth and biofilm formation as result of being in direct contact with oral mucosal surfaces and salivary proteins [40,49]. Both adhesive and composite resins are also susceptible to polymerisation shrinkage upon light-curing which leads to the development of gaps at the tooth-restorative interface, thus creating a pathway for bacterial ingress, colonisation and induction of secondary caries. Recurrent caries is the most common reason for the replacement of dental restorations [50]. The replacement or repair of restorations may lead to compromising of remaining tooth structure and could eventually result in the loss of a tooth [51].

The prevention of plaque accumulation on tooth and restorative surfaces is clinically attempted with (1) pre-treatment disinfectants and oral cavity cleansers (2) the incorporation of leachable antibacterial agents and (3) the inclusion of polymerised or filler particles of QACs into the bonding agents. Pre-treatment of teeth and leachable agents commonly comprise chlorhexidine, glutaraldehyde and benzalkonium chloride as disinfectants in the formulations $[11,52,53]$.

Most of the available commercial dental resin composites are not antibacterial as they are composed of inert inorganic fillers and organic monomers. Some authors have suggested that dental composites may encourage bacterial growth due to the release of ethylene glycol dimethacrylate and triethylene glycol dimethacrylate [54]. Although limited, there are commercially available adhesive systems that have shown antibacterial activity for clinical use in dental applications, such as Clearfil SE Protect (containing MDPB) and GLUMA 2Bond (containing 5\% glutaraldehyde).

Clearfil SE Protect demonstrated good bactericidal activity against several facultative and strict anaerobic microorganisms without reducing dentine bond strength while controlling caries progression in enamel $[11,53]$. Studies have indicated that MDPB displayed moderate cytotoxicity in mouse fibroblasts, odontoblast-type cells and human pulpal cells and is considered acceptable for use in dental applications [55-57]. However, concerns have been raised around the biocompatibility of GLUMA 2Bond due to the cytotoxicity of the aldehyde moiety [53]. Both products eradicated the common cariogenic and periodontic pathogens S. mutans, Fusobacterium nucleatum, Porphyromonas gingivalis, Prevotella intermedia, Prevotella nigrescens, Enterococcus faecalis and Lactobacillus casei [53,58].

The addition of filler particles such as silver, zinc oxide, copper iodide and bioactive glass as well as the polymer chitosan to experimental dental adhesive systems have been reported to impart antibacterial properties [52]. However, a drawback to the use of metallic ions is the resulting colour, which diverges from the natural tooth colour and negatively affects its aesthetic appeal [52,59].

\subsection{Prosthetic Materials and Dental Implants}

The popularity of dental implants has been escalating over the years as it is the preferred treatment option for the replacement of single or multiple missing teeth (Figure 2c) [60]. Despite its success, aseptic loosening and infection of implants are the common reasons 
for clinical failure [61]. The intraoral component of a dental implant is surrounded by gingival crevicular fluid, food debris, saliva, sugars and bacterial metabolites. This creates a microenvironment conducive for microbial growth, particularly for Gram-negative pathogens, which may cause peri-implantitis and periodontitis. Antifouling polymeric coatings deposited onto the surface of metallic screw-in components may enhance the longevity of dental implants by preventing microbial colonisation, infection and subsequent implant failure.

The use of removable partial and complete dentures acts as reservoirs of microorganisms in the mouth. The colonisation of the surfaces of these prostheses put them in constant contact with the oral mucosa. Most commonly, denture stomatitis results from poor oral hygiene and poor denture habits [62]. It is estimated that approximately $70 \%$ of denture wearers suffer from denture stomatitis [63]. The use of an antimicrobial denture base material and antifouling coatings may prevent future recurring infections by managing microbial colonisation and inhibiting biofilm formation, respectively, on the surfaces of these prosthetics. In addition, it would assist denture-wearers in maintaining good oral hygiene and health by preventing the onset of dental diseases. Denture base materials may be transformed into an antimicrobial substrate with the addition of silver and titanium dioxide nanoparticles, chlorhexidine, or the immobilisation of QACs [64]. However, the undesirable leaching of these compounds may adversely affect the health and viability of soft oral tissues and so material properties of water solubility and water sorption should be carefully modulated.

\subsection{Endodontic and Dental-Filling Materials}

The purpose of endodontic treatment is to remove the source of infection in the root canal space (Figure 2d). The root canal treatment process involves instrumentation, irrigation and intracanal medication. This process aims to remove all microorganisms and their products. However, studies have reported that bacteria may remain in the dentinal tubules and cementum which may become sources of inflammation and infection [65]. E. faecalis is the most prevalent microorganism in infected root canals and has the ability to invade deeply into dentinal tubules while resisting intracanal procedures and surviving in filled canals [66]. The development of endodontic medicaments, intracanal posts and resins for core build-ups with antibacterial properties would assist in the repair of apical and periapical tissues [67].

A variety of commercial root canal sealers are available. Antimicrobial agents found in current endodontic sealers include eugenol, zinc oxide, thymol, hexamethylenetetramine, calcium oxide and paraformaldehyde [68]. These components may exhibit toxic effects to host tissues as they lack selective toxicity to microorganisms [66]. Kapralos et al. investigated the antibacterial activity of four commercially available endodontic sealers against Gram-positive planktonic and biofilm bacteria: AH Plus, TotalFill BC Sealer, RoekoSeal and Guttaflow 2 [69]. RoekoSeal displayed no antimicrobial effect. Whilst Guttaflow 2, a polydimethylsiloxane-based sealer, displayed no antibacterial effect despite containing silver microparticles. The commercial sealers AH Plus and TotalFill BC Sealer showed adequate antibacterial properties. The epoxy resin-based sealer, AH Plus, may impart bactericidal activity resulting from the release of formaldehyde constituents during setting [69]. Similarly, methacrylate-resin based sealers may exhibit antibacterial properties due to the low $\mathrm{pH}$ and elution of non-reacted monomers [70]. Silicate-based sealers produce calcium silicate hydrogels and calcium hydroxide during the hydration reaction thereby conferring antibacterial properties to the sealer [66].

\subsection{Regenerative Materials}

The primary motive of using dental regenerative materials is in periodontitis for the formation of new bone and supporting connective tissue (Figure 2e) [71]. Periodontitis is an inflammatory disease affecting the supporting structures of the teeth such as the periodontal ligament, bone and gingiva [72]. If left untreated, periodontitis could eventually lead 
to permanent tooth loss and systemic inflammation [73]. Treatment for periodontal disease includes debridement, radicular conditioning, bone grafting/substitution and guided tissue regeneration in conjunction with the oral administration of antibiotics [74]. As a result of the disease or during treatment processes, root surfaces may be exposed to many bacteria. The success of tissue regeneration may be compromised by local infections caused by microorganisms present in the wound area; therefore, treatment strategies include antibiotic therapy to reduce the risk of wound contamination. Currently, the development of new multifunctional materials to encourage tissue regeneration and minimise local microbial infections are required to improve patient treatment outcomes [71]. Most biomaterials intended for the treatment of periodontitis constitute polymeric advanced drug delivery systems (comprising polymeric nanoparticles, nanofibers, films, chips and thermoresponsive gels) [75] for the sustained release of conventional antibiotic drugs (tetracyclines, metronidazole, clindamycin, ciprofloxacin) [74] into the periodontal intrapocket as targeted therapy. The use of polymeric materials combined with growth factors to promote and support tissue regeneration and healing, may further complicate treatment strategies and lead to treatment failure as they are highly susceptible to microbial accumulation and biofilm formation [76]. The development of novel antimicrobial and antifouling materials, or their inclusion into polymeric composites under investigation, may further assist in reducing the high antibiotic loading dose required in drug delivery applications. This would thereby allay the progression of microbial or antibiotic resistance whilst maintaining a low-microbial environment supportive of healthy tissue regrowth.

\section{Drug-Releasing Antimicrobial Dental Coatings and Resins}

Drug-releasing dental biomaterials constitute a range of polymeric carriers in the form of gels, films, scaffold implants, electrospun nanofibers, nanoparticles or combinations thereof for the controlled release of therapeutic compounds. Common therapeutic compounds for dental applications include antibiotics such as metronidazole, ciprofloxacin, tetracyclines and chlorhexidine as well as non-steroidal anti-inflammatory agents [77]. Most drug-releasing dental biomaterials are designed for the infectious and regenerative treatment of periodontitis whereas others are applied in the synthesis of antibacterial coating materials, dental composites, sealers and adhesives [75,78-81]. Although appropriate for the treatment of periodontitis, drug-releasing dental biomaterials for restorative applications face the challenge of long-term stability, duration of antimicrobial activity and systemic drug exposure. The duration of antimicrobial activity depends on the quantity of drug available for release within the material. Drug elution could also compromise the mechanical integrity of the materials via formation of voids and weakened porous networks after exhaustion of drug release. Coatings are preferred as they do not compromise the mechanical properties of materials and may be reapplied to certain surfaces, such as tooth enamel and exposed implants, when required [82].

\subsection{Chlorhexidine-Releasing Systems}

Over several years, chlorhexidine has remained the gold standard in combating bacterial infections of the oral cavity and is commonly used in mouthwashes at low concentrations as well as in dental composites for antibacterial effect [78]. Concerns of cytotoxicity leading to tissue inflammation, tissue necrosis and reduced regenerative capacity of gingival fibroblasts and periodontal tissues has motivated investigations into long-term chlorhexidine-releasing materials $[83,84]$. Prolonged and localised delivery of chlorhexidine from dental materials embedded within systems such as titanium coatings, tooth enamel coatings, dental resins and composites using biocompatible polymers may reduce cytotoxicity of the drug whilst maintaining adequate antimicrobial and antibiofilm activity. Wood et al. reported sustained drug release from chlorhexidine hexametaphosphate nanoparticles coatings over 99 days due to retention of the nanoparticles within the salivary pellicle coated onto titanium surfaces whereas another group reported drug release over 7 days from coated surfaces of hydroxyapatite discs $[85,86]$. Similarly, chlorhexidine 
has been loaded into porous silica nanoparticles within biocompatible polymeric coatings of polydimethylsiloxane and $\mathrm{pH}$-sensitive polyvinyl pyridine [82,87]. It was reported that an extended 1-week washing period of the nanoparticles could reduce cytotoxicity against gingival fibroblasts by removing surface adsorbed chlorhexidine molecules [87].

Chlorhexidine incorporated into dental resins typically exhibits sustained drug release over a range of 25-29 days [88-92]. Chlorhexidine-loaded montmorillonite composites were shown to minimise interference with mechanical properties (elastic modulus, flexural strength and degree of conversion) of (Bisphenol A bis(2-hydroxy-3-methacryloxypropyl) ether and triethyleneglycol dimethacrylate resin matrices [92]. One group of researchers focussed on the design of antibacterial resin-dentin bonding systems for chlorhexidine delivery inside dentinal tubules of demineralized dentin via polycaprolactone nanocapsules and poly lactic-co-glycolic acid nanoparticles as drug carriers [88,89]. Cytocompatibility testing over $72 \mathrm{~h}$ showed maintenance of dental pulp stem cell viability at $>80 \%$ whereas reduced viability of $<60 \%$ was observed for the maximum level of chlorhexidine-loading in a dose-dependent manner [89].

Whereas the aforementioned delivery systems rely on polymer erosion and diffusion for drug release-Luo and co-workers designed ultrasonic and magnetic controlled chlorhexidine drug delivery systems within urethane dimethacrylate-hydroxyethyl methacrylate (UDMA-HEMA) resins [90,91]. Chlorhexidine-loaded microspheres embedded into UDMA-HEMA resins provided ultrasonic-triggered biphasic drug release over 27 days: constituting a stage of slow release over the first 8.5 days followed by a rapid release over the remaining 18.5 days [91]. The magnetic controlled release system was synthesised by integrating magnetic $\mathrm{Fe}_{3} \mathrm{O}_{4}$ nanoparticles into chlorhexidine crystals. The $\mathrm{Fe}_{3} \mathrm{O}_{4}$-chlorhexidine $0.0005 \%$ UDMA-HEMA resins were able to maintain fibroblast cell viability at $>80 \%$ whilst bacterial viability was practically eliminated [90]. The $\mathrm{Fe}_{3} \mathrm{O}_{4}$ component alone was shown to be non-cytotoxic with $>100 \%$ fibroblast viability and hence it reduced chlorhexidine-induced cytotoxicity. This system is considered to act via a dual antimicrobial mechanism involving (1) the chemical killing action of chlorhexidine and (2) the physical killing action of the metallic nanoparticles. Sustained drug release was achieved over 27 days with cumulative release rates in the range of $4.4-7.4 \%$ where drug release increased upon exposure to a magnetic field. This magnetic-guided drug delivery approach is suggested for incorporation into dental resins, filling materials and denture linings whereas its incorporation into gels and varnishes could be applied for targeted treatment of periodontitis and peri-implantitis [90].

\subsection{Antibiotic-Releasing Systems}

Due to their architectural resemblance to extra-cellular matrices of dental tissues, electrospun nanofibers loaded with antibiotics such as tetracycline, gentamicin and metronidazole have shown to favour cellular regeneration whilst offering antibacterial activity via release of drug molecules $[77,93,94]$. Such systems are investigated primarily as antibacterial coatings for titanium implants for the prevention of peri-implantitis. The advantages of promoting cellular interactions of adhesion and proliferation at the titanium-coating interface assists with implant integration within the host tissues. Tetracyline-loaded nanofibers at $25 \% w / w$ blend of poly(DL-lactide), poly( $\varepsilon$-caprolactone) and gelatine were shown to inhibit biofilm formation and enhance cell proliferation attributed to the activity of tetracycline $[77,93]$. Likewise, non-fibrous thin film coatings of polylactic acid-hydroxyapatitegentamicin and layer-by-layer polyelectrolyte deposition of poly(acrylic acid) (PAA) and poly-l-lysine (PLL) coatings on titanium surfaces (Figure 3) also supported cellular proliferation, proving non-cytotoxicity and antibacterial activity [79,95]. 


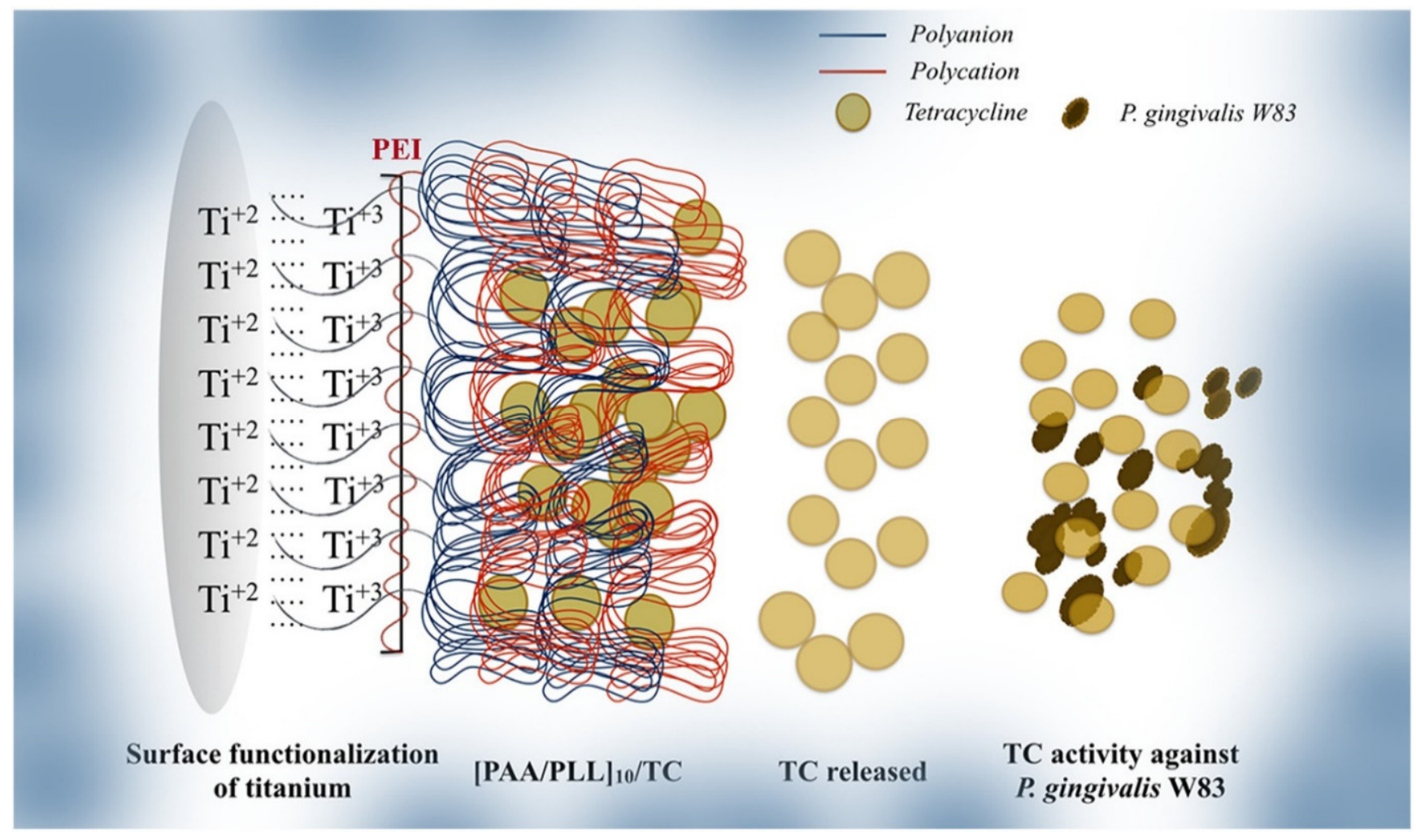

Figure 3. Illustration of the surface functionalization of layer-by-layer polyelectrolyte depositions of PAA and PLL on titanium implants for the sustained release of tetracycline [95]; reproduced with permission from [95], Elsevier B.V. Ltd., 2019.

\section{Antimicrobial Nanoparticle-Based Strategies}

Nanoparticles (particles within a 1-100 nm size range) have been proposed for the treatment of chronic bacterial infections as drug carriers in both a local and systemic drug delivery context $[96,97]$. The antimicrobial agent may either be encapsulated within or conjugated onto the surface of the nanoparticle. Drug cargo can be released from the nanoparticles in a sustained or controlled fashion providing the potential for constant drug levels above the minimum inhibitory concentration (MIC) for sustained killing of the microbes. The material composition of the nanoparticle may also inherently possess antimicrobial and antifouling activity. Such antimicrobial and antifouling mechanisms of nanoparticles are summarised in Figure 4. Recent advances in the composition and design of the nanoparticles have created 'smart' nanoparticles, which are stimuli responsive, capable of mimicking the bacteria in form and function (i.e., biomimetic nanoparticles), incorporating theranostic functionality and modulating immune responses in the host $[98,99]$.

Materials selected to synthesize polymeric nanoparticles may possess bioadhesive properties enabling prolonged adhesion of the nanoparticles to the tissue in the periodontal pocket (for the treatment of periodontitis) or mucosa. Examples of bioadhesive polymers include chitosan, dextran and polyacrylic acid [100]. Nanoparticles can be delivered directly into the periodontal pocket or loaded into films which can be inserted into the periodontal pocket [101]. In relation to the treatment of periodontitis, polymeric nanoparticles and metallic nanoparticles are among the most explored materials to achieve drug delivery and immuno-modulation, as well as antimicrobial action. Polymeric nanoparticles have been under intense investigation in recent times given their greater biocompatibility in relation to metallic nanoparticles [102,103]. 


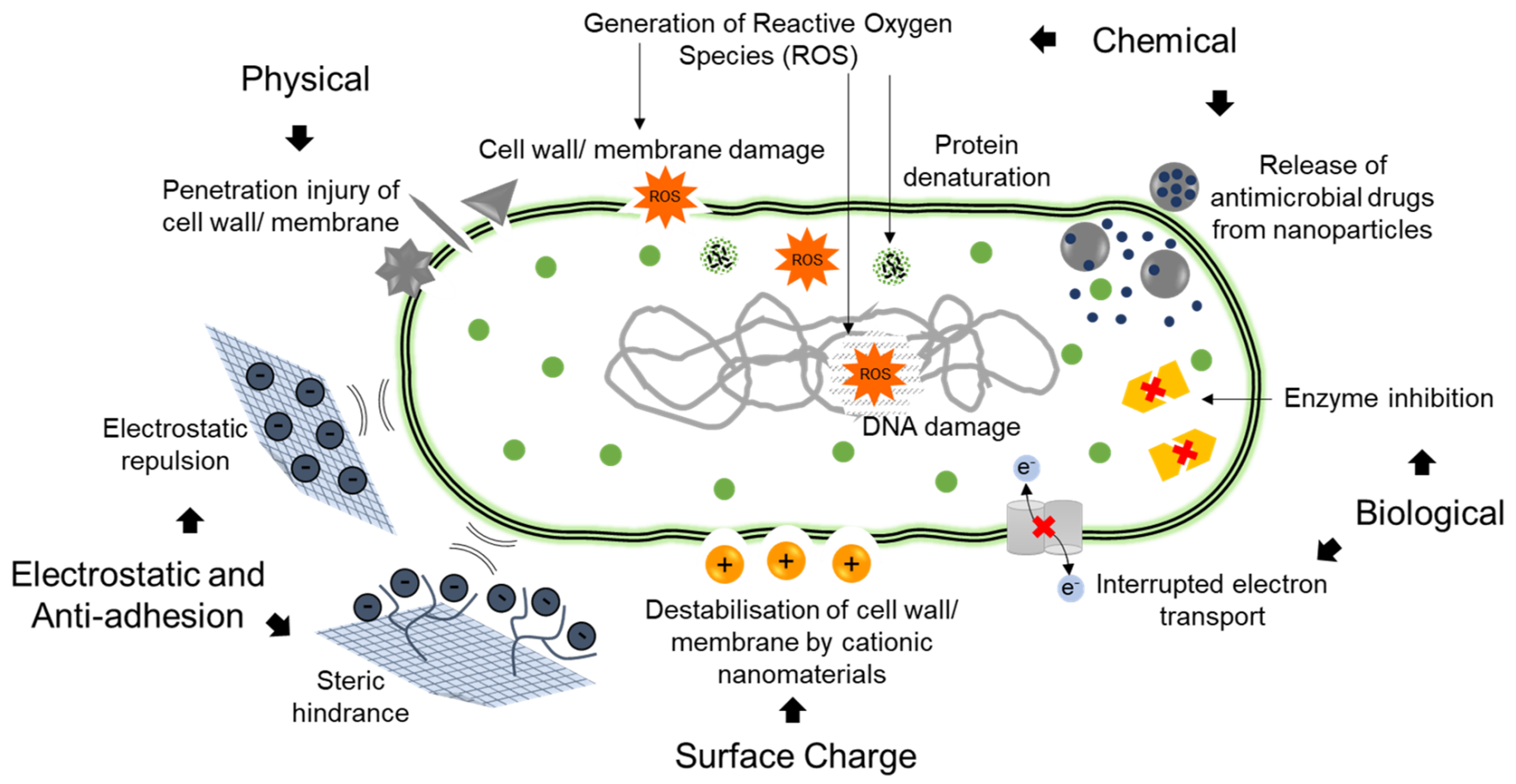

Figure 4. Schematic representation of the antimicrobial and antifouling mechanisms of nanomaterials: physical, chemical, biological, surface charge properties, electrostatic and anti-adhesion properties.

\subsection{Metallic Nanoparticles and Antimicrobial Activity}

Metallic nanoparticles, for example silver (Ag) and the metal oxides of nanoparticles of iron, zinc and titanium are known to disrupt pathogen membranes and generate reactive oxygen species (ROS) which cause mitochondrial damage, cell membrane damage and protein denaturation (as shown in Figure 4) [104]. Other mechanisms of action include inhibition of metabolic processes, displacement of magnesium ions required for the enzymatic activity of oral biofilms, disturbance of the electron transportation, oxidation of macromolecules and prevention of DNA replication [105-108]. The development of resistance is associated with the ability of pathogens to form biofilms, and metallic nanoparticles have widely been investigated as agents to penetrate the biofilm and achieve bacterial reduction.

To reduce cytotoxicity of metallic nanoparticles, green synthesis methods have been employed [109-111]. Several studies have successfully synthesized silver and copper nanoparticles from fungi which are able to reduce the starting materials to produce nanoparticles with antibacterial and anti-inflammatory properties [112-114]. Silver nanoparticles synthesized from the fungi Fusarium semitectum were found to be effective against $P$. gingivalis, Bacillus pumilus, and E. faecalis in vitro [115]. This activity was comparable to that of chlorhexidine. These nanoparticles were also found to be compatible against a human gingival fibroblast cell line [116]. Microbial methods for the synthesis of metallic nanoparticles may be useful for the development of non-toxic, antimicrobial and bioactive dental nanomaterials and this should be explored further in dental pathogens.

To overcome the challenges of chlorhexidine inactivation and cytotoxicity toward human cells, Tokajuk et al. synthesized aminosilane-coated magnetic iron oxide nanoparticles functionalized with chlorhexidine [117]. In the presence of human saliva, the nanoparticles displayed significantly greater bactericidal activity against biofilm-forming microorganisms, including Pseudomonas aeruginosa and E. faecalis, in comparison to free chlorhexidine [117]. The antibiofilm activity of chlorhexidine was improved by the nanoparticles.

Another proposition is the use of multi-metallic nanoparticles for dual biofilm penetration and antimicrobial activity. A combination of two or more metallic nanoparticles may be formulated to take advantage of the synergistic activity of the metals [118]. Holden et al. synthesized $\mathrm{Ag}$ and gold $(\mathrm{Au})$ bimetallic nanoparticles where the incorporated Au reduced 
toxicity of Ag towards cells [119]. The Ag/Au nanoparticles could inhibit the growth of P. gingivalis. Microscopic images indicated damage of the bacterial membrane induced by the nanoparticles [119]. However, more work is required to provide the synergistic activity against periodontitis and caries causing pathogens, and the potential for reduced cytotoxicity against fibroblasts-possibly through combination of $\mathrm{Ag}$ with a benign metal.

The incorporation of Ag nanoparticles into biocide-releasing polymers has also been investigated during the search for dental composites possessing antimicrobial activity. A recent strategy is the incorporation of Ag nanoparticles in 3D printed polymeric dental composite resins which could be further extended to include materials for denture bases, implants and braces [52]. These nanoparticles are thought to exert antimicrobial effects by releasing $\mathrm{Ag}^{+}$ions which coordinate to electron-donating groups, thus disrupting various biochemical processes involving enzymes and DNA [52]. In another study, Cao et al. developed a resin-based dental material with a photocurable core-shell of sliver bromide (AgBr) coupled to a cationic polymer nanocomposite (AgBr/BHPVP) [120]. This composite exerted antibacterial effects against $S$. mutans during the direct contact test through its biocide-releasing mechanism of the $\mathrm{Ag}^{+}$ions as well as a contact-killing mechanism exerted by the cationic polymer and thus showed great promise as an antimicrobial agent which could be incorporated into dental composites, adhesives, cements as well as sealants [120]. The biocompatibility of the AgBr/BHPVP-containing resin disks was assessed using the CKK-8 assay to establish cytotoxicity against RAW 264.7 macrophages. While samples with 0.5 and $1.0 \mathrm{wt} \% \mathrm{AgBr} / \mathrm{BHPVP}$ did not significantly enhance cytotoxicity when compared to pure resin disks alone, $1.5 \mathrm{wt} \% \mathrm{AgBr} / \mathrm{BHPVP}$ reduced cell viability by approximately $50 \%$ [120].

More recently, an antibacterial root canal sealer containing dimethylaminohexadecyl methacrylate (DMAHDM), Ag nanoparticles and amorphous calcium phosphate nanoparticles was developed and tested on bacteria-impregnated human dentin blocks [121]. The root canal sealer containing 5\% DMAHDM, 0.15\% Ag nanoparticles and 30\% amorphous calcium phosphate nanoparticles not only reduced the biofilm CFU of E. faecalis by approximately 3 logs compared to the control, but also demonstrated acid neutralising capabilities which could prove useful in preventing the growth of anaerobic bacteria. As this root canal sealer contained three bioactive agents it was able to inhibit bacteria through both the release of $\mathrm{Ag}^{+}$from the nanoparticles as well as the contact-killing mechanisms of DMAHDM while simultaneously releasing $\mathrm{Ca}$ and $\mathrm{P}$ ions which could remineralize root dentin. This sealer thus demonstrated highly favourable antibacterial and remineralisation characteristics that showed great promise in strengthening tooth root structures and promoting favourable outcomes in endodontic therapy [121].

\subsection{Polymeric Nanoparticles for Drug Delivery and Immunomodulation}

Polymeric nanoparticles are most commonly synthesized from chitosan due to its antibacterial properties, ability for $\mathrm{pH}$ controllable release, bioadhesion and its biocompatibility and biodegradability [122]. Other polymers used for nanoparticle synthesis include polycaprolactone (PCL) and poly(lactic-co-glycolic acid) (PLGA) as they are inert and do not elicit major cytotoxic effects in mammalian cells [123]. Typically, studies involve the encapsulation of a tetracycline (e.g., doxycycline) and the demonstration of antibacterial activity in vitro against periodontitis causing pathogens and in vivo animal models of periodontitis. Immune modulation is also investigated in instances where the immuno-modulatory antibacterial agent doxycycline is encapsulated. Controlled release as well as stimuli-responsive systems based on these polymers have been synthesized and characterized.

$\mathrm{Xu}$ et al. reported the loading of the antimicrobial agent doxycycline into polymeric nanoparticles composed of chitosan and carboxymethyl chitosan [124]. This nanoparticle was anticipated to penetrate the plaque biofilm more effectively and kill the bacteria. The authors reported the bacteriostatic activity of the loaded nanoparticles against $P$. gingivalis. Doxycycline is a well know immuno-modulatory agent, hence this nanoparticle system 
was also investigated as a host-directed immune-therapy for periodontitis. The nanoparticles were reported to effectively down-regulate the mRNA and protein levels of NLRP3 inflammasome and IL-1 $\beta$ in human gingival fibroblasts [124]. The NLRP3 inflammasome plays an important role in regulating innate immune responses in periodontitis [125]. This study therefore demonstrated the capability of nanoparticles to deliver a drug for both antimicrobial activity as well as immune modulation, towards the treatment of periodontitis. Another tetracycline, i.e., minocycline, has also been loaded into chitosan nanoparticles and a characterization of the anti-inflammatory effects was conducted [126]. The nanoparticles were observed to be taken up into endosomes and finally reaching lysosomes (similar uptake and trafficking pathways for P. gingivalis). The nanoparticles were found to induce autophagy which the authors proposed could enhance the therapeutic effectiveness of the nanoparticles through degradation of the intracellular pathogen. The nanoparticles were further shown to exhibit an anti-inflammatory effect, reducing IL-1 mediated activation and downregulation of NF-kB signalling in human gingival fibroblasts [126]. These effects are expected to lessen the pathogen-induced inflammatory burden.

$\mathrm{Hu}$ et al. investigated $\mathrm{pH}$ activatable nanoparticles composed of $\mathrm{N}, \mathrm{N}, \mathrm{N}$-trimethyl chitosan coated lecithin liposomes loaded with doxycycline [127]. The nanoparticles were designed to release doxycycline at low $\mathrm{pH}$ (typically found in the microenvironment of the plaque biofilm). These nanoparticles showed significantly enhanced bacteriostatic activity against $P$. gingivalis and $P$. intermedia, in comparison to doxycycline alone. These nanoparticles could also disrupt the biofilm and in studies conducted using rats, these nanoparticles regulated the activities of osteoclasts and osteoblasts and eliminated inflammation [127].

Calcium fluoride nanoparticles, synthesized due to their higher deposition of fluoride on the tooth and adsorption onto the biofilm, were further loaded together with lignocaine into mucoadhesive films made from thiolated chitosan for prolonged retention of the nanoparticles in the oral cavity. This system was successfully prepared demonstrating suitable mechanical strength, bioadhesion, drug release and permeation enhancement [101]. Echazú et al. reported the development of $\mathrm{pH}$-responsive biopolymer composites, composed of silica nanoparticles in chitosan hydrogels [128]. The composites were loaded with a plant extract comprising antioxidant properties. The composites were reported to increase fibroblast proliferation thereby providing an environment for bone remineralization. Polymeric nanoparticles of PCL encapsulating the anti-microbial agent triclosan were synthesized by Aminu et al. These nanoparticles were further loaded into a chitosan nanogel containing the non-steroidal anti-inflammatory drug flurbiprofen. An in vivo study in rats demonstrated the dual-activity of the nano-formulation providing resolution of gingival inflammation and reduction of accumulated plaque [129].

To improve drug retention at the biofilm-apatite interface, Sims Jr and co-workers investigated the dual release of myricetin and farnesol encapsulated within tooth-binding nanoparticles of poly(dimethylaminoethyl methacrylate)-b-poly(dimethylaminoethyl methacrylateco-butyl methacrylate-co-propylacrylic acid) (p(DMAEMA)-b-p(DMAEMA-co-BMA-coPAA) $[130,131]$ for antibacterial activity against $S$. mutans biofilms. Improved toothbinding electrostatic affinity of the system was attributed to bound myricetin on the cationic corona of the nanoparticles, therefore, enabling this delivery system to serve as an in situ drug reservoir at the saliva coated tooth surface for biofilm inhibition in dental caries [131].

An interesting therapeutic modality in the treatment of periodontitis is photodynamic therapy. This approach involves a photosensitizer, which is excited through exposure to light to generate ROS which kill the bacteria. Indocyanine green is such a photosensitizer and Rad et al. reported the loading of indocyanine green into chitosan nanoparticles [132]. Results showed that photodynamic therapy through the nanoparticles led to a reduction in the expression of biofilm formation-related gene (rcpA) of Aggregatibacter actinomycetemcomitans and this reduction was far more than that induced by indocyanine alone [132].

It is exciting to note that at least one PLGA nanosphere formulation containing doxycycline has undergone clinical trial testing as an adjunctive therapy in the treatment of 
chronic periodontitis in individuals with type-2 diabetes mellitus. This study was a parallel, double-blind, randomized, placebo-controlled clinical trial and data for 40 individuals was analysed receiving either a placebo of PLGA nanoparticles or doxycycline loaded nanoparticles. Locally applied doxycycline loaded PLGA nanoparticles favoured cytokine modulation and microbial reduction and were able to additionally reduce pockets and bleeding on probing in the patients [133]. This study shows the clinical promise of polymeric drug loaded nanoparticles as dental materials in the treatment of periodontitis.

A drawback to the inclusion of antimicrobial nanoparticles within dental restorative, treatment and replacement materials is the compromised mechanical integrity attributed to the clustering or leaching-out of the incorporated nanostructures, resulting in the formation of weak regions throughout the material matrix. A study by Makvandi and co-workers investigated the design of a photocurable non-diffusible and non-leaching antimicrobial quaternary ammonium methacrylate resin modified with silica nanoparticles (QMSN) for enhanced mechanical properties [134]. Compared to unmodified commercial dental resin, the QMSN system demonstrated improved flexural strength and modulus with sufficient antimicrobial activity and lower fibroblast cytotoxicity at a concentration of $2.5 \%$. Although higher QMSN concentrations of $5-10 \%$ increased antimicrobial activity and mechanical strength, cell viability was greatly reduced to levels in the range of $15-30 \%$ [134].

\section{Antimicrobial and Antifouling Polymers}

Antimicrobial polymers have gained increasing popularity over the past decade as they offer several advantages over traditionally used antibiotic drugs such as superior efficacy and selectivity, prolonged shelf-life, decreased toxicity, reduced environmental harm and reduced occurrence of antimicrobial resistance as well as being impervious through skin $[135,136]$. Antimicrobial polymers are classified depending on the mechanism of biocidal activity, as depicted in Figure 5: (1) polymeric biocides, (2) biocidal polymers and (3) biocide-releasing polymers $[137,138]$. Biocidal polymers possess intrinsic antimicrobial activity within their structure and contain cationic moieties such as quaternary ammonium, tertiary sulfonium, phosphonium and guanidium [138]. The cationic moiety exerts antimicrobial effects by destabilising the negatively charged cell membrane of microbes [139]. Polymeric biocides comprise bioactive repeating units of amino, carboxyl or hydroxyl groups covalently bound to the polymer backbone and act via microbial repulsion or anti-adhesion (rather than killing action) for antifouling properties [138]. Both biocidal polymers and polymeric biocides exert their antimicrobial and antifouling effects, respectively, upon direct contact with the microorganism; whereas biocide-releasing polymers act as a platform for the release of small molecule biocides delivered to the surrounding environment $[138,140]$. 


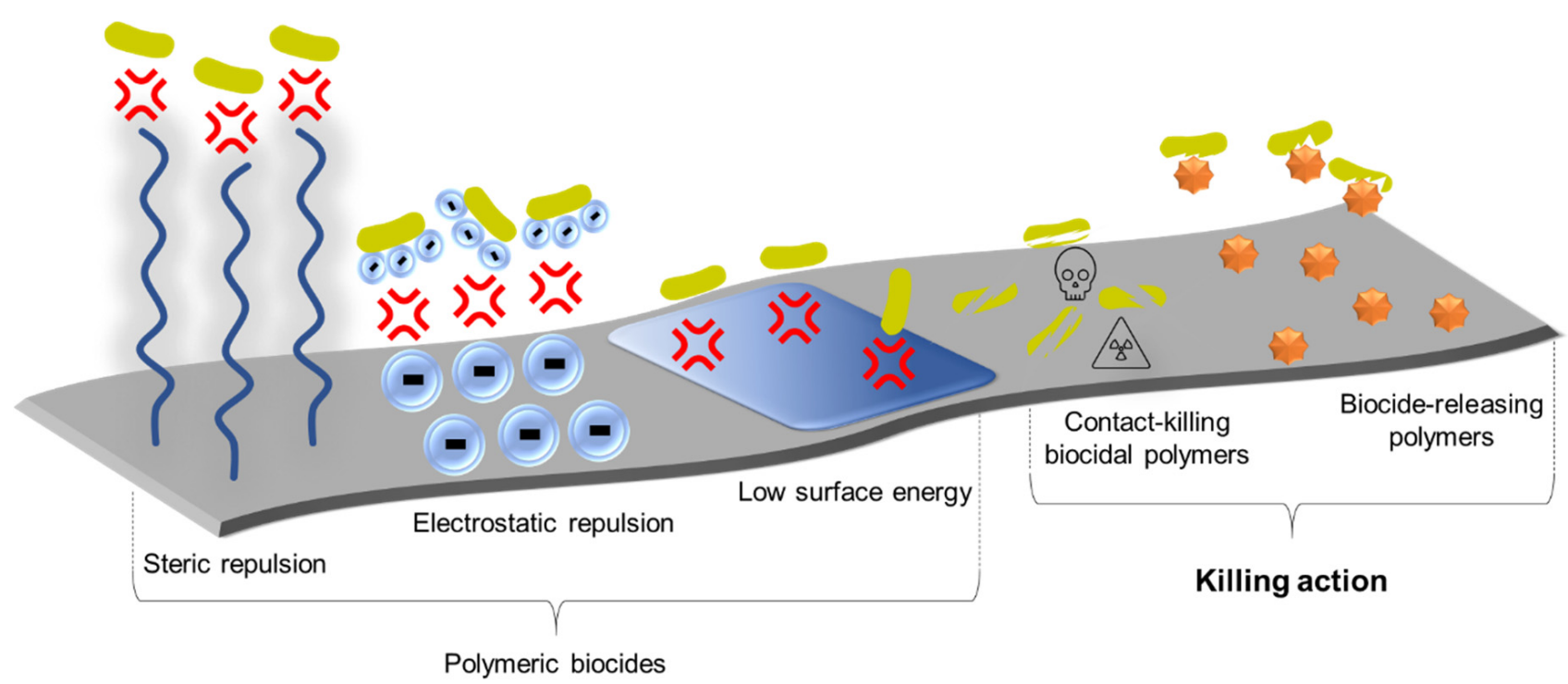

Repulsion and anti-adhesion

\section{Antifouling}

Antimicrobial

Figure 5. Illustration of the mechanisms of action of the different classes of antimicrobial polymers: polymeric biocides, biocidal polymers and biocide-releasing polymers.

\subsection{Antimicrobial Quaternary Ammonium Compounds}

Of the biocidal polymers, quaternary ammonium compounds (QACs) are heralded as classic and highly effective, yet cytotoxic, disinfectant agents in the medical, pharmaceutical and industrial setting. The mechanism of action of the antimicrobial effects of QACs is a result of contact-killing via electrostatic interaction and subsequent disruption of negatively charged bacterial cell walls by cationic QAC molecules [141]. The first commercial use of QACs for dental applications was initiated by its development in 1994 by Imazato and colleagues with the novel synthesis of the 12-methacryloyloxydodecylpyridinium bromide (MDPB) monomer [10]. The QAC in the MDPB methacrylate-based resin provides disinfectant properties prior to polymerization with bacteriostatic effects post-curing [10] Previous studies indicated that MDPB displays moderate cytotoxicity in mouse fibroblasts, odontoblast-type cells and human pulpal cells which is considered acceptable for use in dental applications [55-57]. Since then, incorporating QACs as monomers and microand nanofillers in the synthesis of non-leaching antimicrobial dental composite resins and adhesives for restorative applications have garnered much interest [58].

Recent research in the investigation of QAC monomers for antimicrobial methacrylate dental composite resins and adhesives is focussed on the exploration of novel quaternized materials capable of non-leaching contact-bactericidal effects for maintaining low cytotoxicity and optimal mechanical properties, flexural strength and modulus, after curing. Contact-killing antimicrobial surfaces may be the favourable option as the activity of biocide-releasing polymers is anticipated to be depleted at some point. Biocide-releasing polymers are thus associated with disadvantages including a limited shelf-life and a higher potential to promote antimicrobial resistance as the concentration of the biocide compounds released gradually approaches depletion. Antimicrobial polymers could overcome these problems through the irreversible immobilisation of the biocidal molecules on the polymer [142].

To address compromised mechanical integrity resulting from miscibility of QACs with commercial dental resins, the quaternary ammonium dimethacrylate monomer $\mathrm{N}, \mathrm{N}-$ bis (2-(3-(methacryloyloxy)propanamido)-ethyl)-N-methylhexadecyl ammonium bromide (IMQ-16) was incorporated into a diurethane dimethacrylate (UDMA)/tricyclodecane 
dimethanol diacrylate (SR833s) resin system [143]. The IMQ-16-UDAM/SR833s resin demonstrated antimicrobial effects against $S$. mutans yet of comparable mechanical strength to the bisphenylglycidyl dimethacrylate (Bis-GMA)/triethylene glycol dimethacrylate (TEGDMA) resin system in terms of flexural strength and modulus. The authors further hypothesized improved biocompatibility of IMQ-16 loaded polymer systems, compared to Bis-GMA/TEGDMA, owing to lower water solubility [143]. The properties of water solubility and water sorption modulate mechanical strength and biocompatibility of antimicrobial resin systems as water penetration and polymer dissolution results in gradual mechanical failure and the release of potentially cytotoxic unreacted monomers.

The antibacterial mechanism as well as biocompatibility of QACS is further influenced by the alkyl chain length of the compound. It has been known that increasing alkyl chain length, to a certain limit, enhances antibacterial activity whereas any further increases beyond the limit results in reduced activity [139]. In contrast, decreasing chain lengths have been associated with increased biocompatibility. $\mathrm{Li}$ and co-workers developed new shortchained quaternized pyridine dimethacrylates derived from niacin (vitamin B3) for the synthesis of an antibacterial dental resin with the objective of enhancing biocompatibility of the system [144]. Although no biocompatibility studies were reported in the paper, the authors anticipate that the presence of niacin would have a positive effect on cell viability and have acknowledged cytocompatibility testing in future [144].

With increased focus being placed on biocompatibility of these much needed antibacterial and antifouling dental restorative materials, Silva et al. investigated keratinocyte cytocompatibility and ultimate tensile strength of myristyltrimethylammonium bromide (MYTAB)incorporated dental resins. MYTAB concentrations of $2 \%$ decreased bacterial growth with no adverse effects on tensile strength whereas concentrations of $1 \%$ significantly displayed stunted cell viability to a region of $50 \%$. The researchers proposed that a $0.5 \%$ concentration would confer sufficient antibacterial activity to the dental resins yet maintain compatible physical and chemical stability and biocompatibility (approximately 90\%) [145].

With initial reports of its synthesis, by Li and co-workers, dimethylaminohexadecyl methacrylate (DMAHDM) has stimulated interest in the evaluation of its QAC antimicrobial and biocompatibility properties [146]. An interesting study investigating the $r n c$ gene deletion of $S$. mutans with DMAHDM displayed considerable antibacterial effects within a dental resin compared to the activity of the commonly used germicide, chlorhexidine [147]. The reported observations of reduction in biofilm biomass, polysaccharide and lactic acid production, may hold promise for the combined strategy of bacterial gene modification with QAC-incorporation for the fabrication of antimicrobial dental composite resins.

\subsection{Antifouling Zwitterionic Polymers}

As a new generation of polymers, zwitterionic materials have shown promising appeal for the development of novel biocompatible antifouling biomaterials for a range of dental applications involving resins, adhesives, cements, composites, coatings, varnishes and sealants $[148,149]$. Zwitterionic materials contain both cationic and anionic functional groups yet have an overall neutral charge. Its molecular arrangement mimics the phospholipid bilayer in cell membranes with the hydrophilic heads directed outwards and the hydrophobic tails inwards [149-152]. As superhydrophilic protein-repellent polymers they contain hydrogen-bond acceptors rather than donors. This enables the material to form a hydration shell via electrostatic interaction which imparts its protein-repellent and antifouling ability $[149,153,154]$. By inhibiting salivary protein adsorption to dental and mucosal surfaces, bacteria have no base for attachment due to reduced coverage of the salivary pellicle thus resulting in prevention of biofilm formation [151]. The zwitterionic polymer, 2-methacryloyloxyethyl phosphorylcholine (MPC), is an established non-toxic material widely used in biomedical applications as biocompatible coatings for metallic implants, catheters and artificial tissues [154]. Early studies indicated that MPC coatings reduced the adherence of common biomedical device colonizers and periodontal pathogens on 
plastic coverslips and hydroxyapatite disks, respectively $[155,156]$. Bioprotective effects of MPC were further evidenced on human oral keratinocytes against inflammation-induced damage from commercial oral disinfectants, such as cetylpyridinium chloride [150]. These studies inspired experimentation of MPC and other zwitterions within dental materials for protein-repelling antifouling properties.

Zhang and co-workers were among the first to investigate MPC for the synthesis of a protein-repellent dental adhesive and composite for the prevention of biofilm-induced secondary caries $[13,148]$. In addition, this group explored the combination of MPC and DMAHDM, for dual action microbial-repellent and antimicrobial activity, within a glassbased dental resin composite [157]. Combining zwitterionic polymers with QACs may offer enhanced antimicrobial effectiveness of QACs in dental materials. It is postulated that the contact-killing antimicrobial mechanism of QACs may be reduced when dental surfaces are coated with a salivary pellicle $[12,146,158]$. By inhibiting salivary protein adhesion and reducing salivary pellicle production, contact-killing between the QACmicrobial interface improves while the protein-repellent action of zwitterionic material prevents biofilm formation $[148,152,159]$. The further inclusion of calcium phosphate into MPC-DMAHDM composites imbues a trio of (1) antimicrobial, (2) antifouling and (3) remineralizing rechargeable properties to dental adhesives, sealers and resins $[23,160,161]$.

With its well-known antifouling and biocompatible appeal as well as its simplicity of incorporation with other materials, several studies emphasized the impact on mechanical properties of dental materials upon MPC integration. Zhang and co-workers reported similar mechanical properties to that of a BisGMA/TEGDMA commercial control at MPC concentrations up to $3 \% \mathrm{wt}$ whereas concentrations exceeding $4.5 \% \mathrm{wt}$ led to compromised mechanical integrity $[148,157]$. Lee et al. showed that MPC incorporated into a commercial surface pre-reacted glass-ionomer filler (SPRG) at concentrations within 1.5-5\% wt displayed adequate antifouling and mechanical strength of $80 \mathrm{MPa}$ (conforming to ISO 4049 standards); however, concentrations exceeding 5\% wt resulted in significant reduction in flexural strength imparted by increased water solubility, water sorption and wettability [162]. Similarly, an orthodontic bonding agent comprising MPC mixed with mesoporous bioactive glass nanoparticles (MBN) also demonstrated mechanical failure and reduced protein-repellent activity with MPC concentrations exceeding $5 \% \mathrm{wt}$ due to gelation of the polymer resulting from its affinity to moisture [152]. To avoid mechanical compromise of the bulk dental material, MPC could be photochemically conjugated onto the surface of filled composite resins during the dental procedure, however, this requires dental procedures to be short and simple with the use of safe solvents for rinsing out unreacted monomers in the oral cavity [163].

In addition to MPC, Kwon and colleagues recently investigated another zwitterionic polymer, sulfobetaine methacrylate (SB), in dental resin composites, varnishes and cements to impart antifouling properties and mechanical durability $[149,159,162,164]$. With 3Dprinting as a popular synthesis technique for polymethyl methacrylate (PMMA)-based dental materials, the authors expressed the necessity for evaluations of mechanical integrity while maintaining optimal antifouling action and tissue biocompatibility. In a new study, the addition of MPC or SB in PMMA 3D-printed dental resins demonstrated similar antifouling performance and minimal degradation at zwitterion concentrations in the range of 3-5\% wt; although the degradation resulted in reduced mechanical properties, the material strength complied with the International ISO 20795-2 requirements [149].

To evaluate its clinical significance, Ikeya et al. polymerized MPC with $n$-butyl methacrylate and photoreactive monomer 2-metahcryloyloxyethyl-4-azidobenzoate (PMBPAz) as an antifouling coating for dentures [165]. The PMBPAz coating showed potential to significantly reduce the percentage plaque index on the coated dentures (as shown in Figure 6) of 11 participants and was able to withstand chemical and mechanical stressors of the oral cavity for 2 weeks-after which time reapplication would be necessary [165]. Demonstrating its clinical performance, a significant reduction in the oral counts of F. nucleatum and Streptococci spp. was observed within $5 \mathrm{~h}$ in a crossover trial 
consisting of 20 participants after rinsing with $5 \mathrm{~mL}$ of a $5 \%$ MPC-polymer mouthwash for $20 \mathrm{~s}$ [151]. These studies confirming the antifouling effects and safety of MPC in vivo, holds promise for forthcoming studies of this nature, clinical trials and subsequent use of MPC-functionalised dental materials in the clinic.
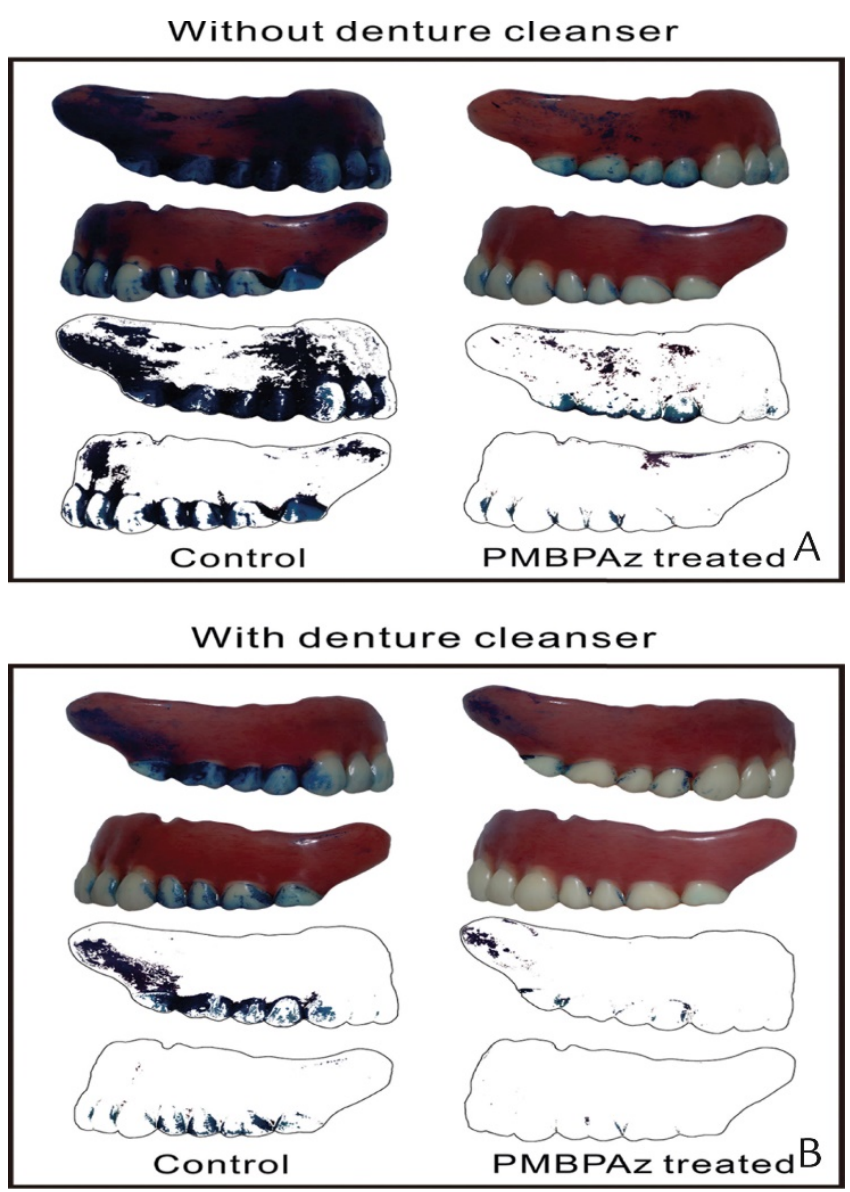

Figure 6. Plaque deposition on maxillary complete denture after 2 weeks. (A) Total denture area of polished surface after staining and digitization: left, control; right, PMBPAz treated; and plaque area of polished surface after selection without denture cleanser. (B) Total denture area of polished surface after staining and digitization: left, control; right, PMBPAz treated; and plaque area of polished surface after selection with denture cleanser [165]. Reproduced with permission from [165], Elsevier B.V. Ltd. (C) 2021, RightsLink.

\section{Antimicrobial Peptides}

Antimicrobial peptides (AMPs) are host-derived endogenous biomolecules forming part of the innate immune system in microorganisms, plants and animals. APMs are short amphipathic cationic peptides featuring broad spectrum antimicrobial activity against Gram-positive and Gram-negative bacteria, fungi and viruses; rapid onset of action, low risk of generating antimicrobial resistance, high biocompatibility and capability of modulating the immune system $[32,37,166]$. These properties have driven their popularity as promising candidates for the development of antimicrobial surfaces for controlling the growth of cariogenic and periodontic pathogens. Following its uptake via direct penetration or endocytosis, the bactericidal mechanisms of AMPs involve: (1) plasma membrane permeabilization and disruption, (2) intracellular targeting of molecules and processes for inhibition of functional microbial proteins, (3) interruption of DNA and RNA synthesis and (4) immunomodulation and stimulation of non-inflammatory host immune responses for microbial clearance $[37,138,167]$. 


\subsection{Synthetic AMPs for Dental Applications}

Naturally occurring AMPs are used as design templates for a wide range of synthetically produced and modified derivatives $[138,167,168]$. Although natural and synthetic AMPs offer the same bactericidal mechanisms, synthetic derivatives are favoured as they overcome several limitations of natural AMPs such as susceptibility to inactivation by salivary proteolysis, hydrolysis and enzymatic degradation, as well as properties of cytotoxicity, haemolytic activity, poor tissue distribution and improved eradication of multidrug-resistant bacteria [37]. Described below are some examples of recent synthetic AMPs that have shown relevance for biocompatibility, antimicrobial and antifouling action in dental materials. For a comprehensive list of natural and synthetic AMPs over the past several years that have been investigated for dental applications, the reader is directed to a review by Niu et al. [169].

The synthetic peptide, GH12, showed high and rapid in vitro antimicrobial activity against S. mutans, Streptococcus salivarius and Streptococcus sobrinus by inhibiting biofilm formation as well as metabolic activity in biofilms [160,170,171]. In vitro cytotoxicity assays found that GH12 induced low toxicity in human gingival fibroblasts (HGFs) at concentrations of $128 \mu \mathrm{g} / \mathrm{mL}$ over a $2 \mathrm{~h}$ incubation period [160]. These properties were confirmed in vivo where GH12 reduced the incidence and severity of caries without causing any damage to the oral mucosa or other signs of ill health in rats [172]. Jiang and co-workers further showed that antimicrobial and antibiofilm activity of GH12 was improved at $\mathrm{pH}$ 5.5 than at $\mathrm{pH} 7.2$, therefore, making this AMP a suitable candidate for the development of $\mathrm{pH}$-responsive smart biomaterials in the acidic microenvironment of dental caries [173].

The novel anticancer peptide, ZXR-2, demonstrated antimicrobial activity by rapidly eliminating cariogenic bacteria and inhibiting the formation of $S$. mutans biofilms, however, its effectivity against mature biofilms was limited [174]. Furthermore, at $4 \times$ MIC, ZXR-2 produced $30 \%$ lysis of mammalian red blood cells after a $3 \mathrm{~h}$ incubation period, thus indicating acceptable cytotoxicity for the prevention and treatment of dental caries [174]. The authors acknowledged the need for improved antibiofilm activity and reduced cytotoxicity of ZXR-2 for its use in dental products such as mouthwashes and toothpastes.

Another synthetic peptide CLP-4 demonstrated stability against salivary proteases, showed strong antibacterial activity against cariogenic $S$. mutans, inhibited biofilm formation and moreover, eradicated established biofilms at $50 \mu \mathrm{g} / \mathrm{mL}$ (at $10 \times \mathrm{MIC}$ )—a valuable property that some conventional antibiotics, such as the control erythromycin, do not possess [175]. CLP-4 caused $<10 \%$ haemolysis in human red blood cells within an hour at concentrations between 8 and $1000 \mu \mathrm{g} / \mathrm{mL}$ and moderate cytotoxicity against human oral fibroblasts at concentration of $5-51 \mu \mathrm{g} / \mathrm{mL}$ after $72 \mathrm{~h}$ incubation, hence, its potential or development into an antibiotic for dental caries [175].

To mimic the activity of commonly used fluoride for protection against caries and promotion of its repair, Wang and co-workers, synthesised a novel bifunctional AMP featuring antibacterial remineralising properties [176]. The peptide TVH19 displayed the highest bactericidal activity against $S$. mutans and remineralisation potential among the set of three peptides (TVH19, TDH19 and TNH19) that were synthesised. This AMP was capable of inhibiting biofilm formation at $32 \mu \mathrm{M}$, disrupting viability of pre-formed biofilm at $128 \mu \mathrm{M}$ and maintaining chemical stability of $86.71 \%$ after $12 \mathrm{~h}$ incubation in human saliva; while in vitro cytotoxicity studies in human oral keratinocytes showed similar cell viability of distilled-deionized water and $512 \mu \mathrm{M}$ TVH19 [176]. Further studies involving multispecies biofilms, pellicle formation, salivary flow and temperature in a well-simulated oral cavity model is anticipated to precede this first report of bifunctional AMPs [176].

Despite its potent antimicrobial activity and inhibition of biofilms, AMPs perform poorly in the oral cavity due to rapid enzymatic degradation, poor target specificity in solution, anionic protein adsorption and the diluting effects of saliva which render the compound ineffective [167-178]. Therefore, strategies are required to improve its physiological in vitro and in vivo stability to harness the maximum antimicrobial and antifouling effects of this exciting class of biomaterials. 


\subsection{AMP Tooth-Binding Strategies}

To overcome the challenges of stability in the oral cavity, Huang and co-workers designed a hydroxyapatite (HAp)-binding antimicrobial peptide (HBAMP) conjugate with the AMP KSL-W as a contact-active antibacterial interface on tooth surfaces to inhibit biofilm formation [167]. Rapid and high binding of HBAMP to HAp surfaces provided up to $65 \%$ S. mutans elimination, as shown in Figure 7, as well as improved stability in saliva [167]. Cytocompatibility was ascertained by proliferation of human gingival fibroblasts, however, exposure of $500 \mu \mathrm{g} / \mathrm{mL}$ HBAMP over $4 \mathrm{~h}$ caused disruption in cell membranes and lactic acid dehydrogenase leakage in a time dependant manner [167].

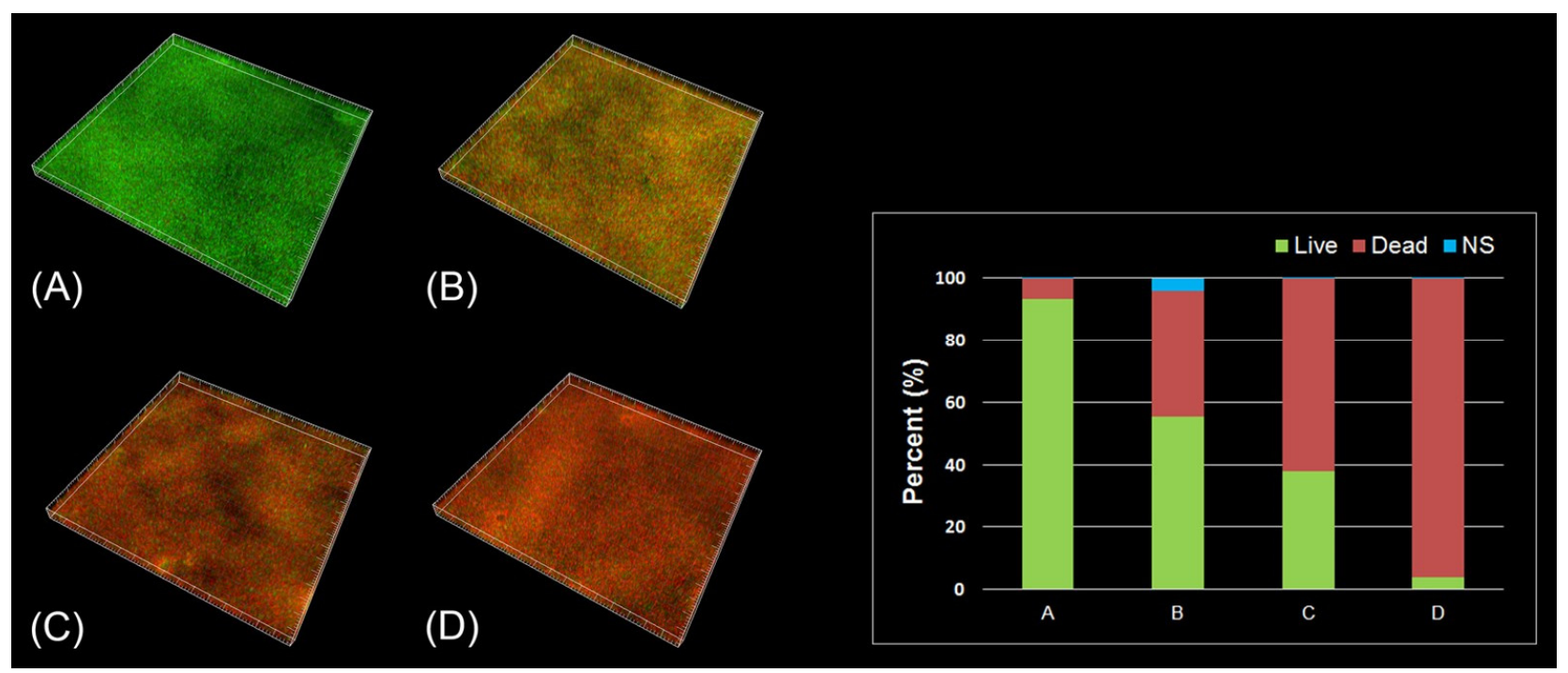

Figure 7. Confocal laser scanning microscope images of S. mutans biofilms and the percentage of live/dead cells. (A) The biofilms without treatment were performed by the same process as the control; (B) The biofilms were cultured for $12 \mathrm{~h}$ and then treated with $250 \mu \mathrm{g} / \mathrm{mL}$ hydroxyapatite (HAp)-binding antimicrobial peptide (HBAMP); (C) $500 \mu \mathrm{g} / \mathrm{mL} \mathrm{HBAMP}$ for $10 \mathrm{~min}$; (D) 0.12\% chlorhexidine for $10 \mathrm{~min}$. [167]. Reproduced from [167] @ Creative Commons CC BY 4.0. Copyright 2016, Springer Nature.

In another study, Zhang et al. grafted the antimicrobial polyphemusin I (PI) to diphosphoserine (DPS) for the synthesis of a tooth-binding DPS-PI AMP. Cytocompatibility studies using bone mesenchymal stem cells (BMSCs) revealed no cytotoxicity after $5 \mathrm{~d}$ thus making DPS-PI biocompatible. To determine the ability of DPS-PI to prevent dental plaque biofilm formation in vivo, the incisors of New Zealand white rabbits were coated with DPSPI for one minute and then washed off with sterile water. Following the administration of a high-sucrose diet for $48 \mathrm{~h}$, DPS-PI was found to significantly reduce the growth of dental plaque biofilms on the rabbit tooth surfaces [179]. Further studies are required to improve the antimicrobial efficacy of DPS-PI and explore its safety profile before its development into oral hygiene dental products for consumers.

A recent study investigated the applicability of a modified dual function (antimicrobial and remineralising activities) AMP, phospherine-grafted-histatin 5, for higher HAp-binding affinity to tooth surfaces in the treatment of decayed teeth [180]. The AMP histatin 5 contains cationic amino acid residues which elicit a bactericidal effect via inducing membrane permeability and damage to intracellular DNA of microbes as well as promote its adsorption to tooth surfaces for forming a bioactive coating with antibiofouling effects and in situ self-healing of carious lesions [180]. 


\subsection{AMP Release-Based Strategies}

Another approach to protect AMPs in physiological conditions is its incorporation into liquid crystalline systems (LCS) for the controlled release of AMPs as an alternative to antibiotic delivery. This carrier system is useful in the delivery of peptides as it offers the sensitive molecules protection against the harsh degradative mechanisms in the oral cavity $[178,181]$. Formulating the AMP-LCS with bioadhesive properties further ensures prolonged contact with tooth and oral mucosal surfaces for bacterial and biofilm control as shown by systems loaded with p1025 and KSL-W into a mucoadhesive liquid crystalline carrier for controlled release of the AMPs within the oral cavity via buccal administration $[178,181]$. Similarly, Aida et al. investigated the AMP $\beta$-defensin-3 peptide fragment (D1-23) in an LCS for the prevention of dental caries which demonstrated antibiofilm activity and no cytotoxicity in epithelial cells [182]. In a unique study, KSL-W was incorporated into an antiplaque drug delivery chewing gum with Phase 2 clinical studies showing that the chewing gum successfully inhibited the regrowth of dental plaque in the absence of other oral hygiene methods during a 4-day test period [183].

A gelatinous blend of the AMP NaI-P-113 was injected into the periodontal pocket in patients with periodontitis at a concentration of $20 \mu \mathrm{g} / \mathrm{mL}$ [184]. The release of Nal-P-113 exerted its antimicrobial effects by perforating the cytoplasmic membrane and causing cytoskeletal collapse in P. gingivalis, F. nucleatum, and Streptococcus gordonii. This clinical trial showed that Nal-P-113 administered in gelatine decreased the pocket depth and bleeding index values and thus successfully alleviated gingival inflammation by entering the subgingival dental plaque [184]. It would be interesting to further explore periodontal intrapocket drug delivery systems using AMPs as a replacement for conventional antibiotic drugs due to their reduced propensity of developing microbial resistance. However, being large protein molecules, their permeation through mucosal membranes as well as polymeric matrices and bioactive stability in the oral cavity are key challenges that must be overcome for effective clinical applications.

\subsection{AMP Immobilisation and Conjugation Strategies}

Although AMPs have recently shown great appeal as dental implant coatings and formulation additives in adhesive materials, its successful commercialisation for dentistry remains limited due to toxicity resulting from the need for high effective doses, the potential for immunogenicity and its sensitivity to ion strength [185]. To mitigate these issues, the retention of AMPs on implant and adhesive surfaces via physical adsorption or chemical immobilisation has been proposed to attach AMPs to the biomaterial surface [186].

The antimicrobial peptide, nisin, was incorporated into a commercial adhesive product, Adper Single Bond 2, by means of non-specific adsorption to imbue it with antimicrobial properties. The cured nisin-incorporated dental adhesive successfully demonstrated an inhibitory effect against the growth of $S$. mutans in a dose dependent manner. However, in agar diffusion tests, no significant differences were noted between the cured nisin-incorporated adhesive and the control formulation which may indicate that the antimicrobial effect of nisin is confined within the adhesive system only with no leaching of the peptide [187]. It was previously shown that nisin influences neither the proliferation nor the viability of oral human cells at antimicrobial and anti-biofilm concentrations [188] and did not demonstrate any apparent oral toxicity in F344 rats during a 90-day oral toxicity study [189].

Another study utilised a simple one-step soaking method to adsorb modified AMPs, GH12-M1 and GH12-M2 (containing a single lysine residue), to a commercial dental adhesive formulation blended with $\varepsilon$-polylysine for enhanced antimicrobial activity at the dentin-adhesive interface [190]. Here, $\varepsilon$-polylysine blended in a dental adhesive system facilitated the immobilisation of the AMPs to the surface of the material, however, it would be noteworthy to evaluate the duration of stability, antimicrobial activity and any potential for AMP cleavage resulting in its release in the oral cavity. 
Recently, Xie et al. aimed to overcome the limitations of non-specific adsorption techniques, such as reduced antimicrobial efficacy and potential leakage of the peptide out of the resin material, by covalently conjugating the GH12-derived AMP with a monomer commonly used during the formulation of dental adhesives [185]. To further improve the flexibility between the resin material and the peptide, spacer domains were integrated, and the resultant AMPs were then conjugated to methacrylate and finally copolymerised into dental adhesives. The resultant polymethacrylate-based AMP conjugated matrix demonstrated substantial antimicrobial effects against S. mutans [185].

Despite being an effective means for non-leaching chemical immobilisation, covalent conjugation may induce structural constraints to AMPs which could adversely alter antimicrobial activity. Another drawback to covalent conjugation procedures is that it can only be conducted before implantation as the processes are usually carried out under harsh conditions that cannot be conducted intraorally [186]. To this end, Moussa et al. exploited the amphipathic properties of AMPs during their attempt to create a peptide-based two-tier protective strategy at the dentin-restoration interface to address the high failure rate of adhesive restorations [191,192]. This hydrophobic system hampers the degradative effects of water and waterborne agents while simultaneously providing antibiofilm protection via coating/priming dentin with GL13K - an amphipathic AMP derived from an oral peptide - to obtain dentin that is resistant to recurrent caries around the bonded restoration areas. In addition, GL13K maintained adequate cell viability of murine embryonic fibroblasts (NIH 3T3) and human dental pulp cells (hDPCs) over a $24 \mathrm{~h}$ incubation period at a concentration of $200 \mu \mathrm{g} / \mathrm{mL}$ [191,192].

Another interesting application of AMPs is their incorporation into hydrogel scaffolds for tissue engineering purposes, however, most AMP-containing hydrogels developed to date exhibited low mechanical strength which raises concerns regarding their durability in load-bearing applications in dentistry. Attempts have also been made to integrate AMPs into polymer systems, however, limited success has been reported to date [185]. An alternative application of AMP-containing hydrogel scaffolds is attachment to implant surfaces as bioadhesive coatings. To demonstrate the technique, a hydrogel containing the AMP cateslytin was utilised for antimicrobial efficacy against $P$. gingivalis in the development of peri-implantitis [193]. The supernatant of the cateslytin hydrogel induced no toxicity in HGF-1 human gingival fibroblasts over a 72-h incubation period and did not alter the viability of the fibroblasts. This hydrogel thus demonstrated good cellular biocompatibility and could be attached to the surface of titanium dental implants [193].

Other studies investigating the attachment of AMPs to titanium implant surfaces via covalent binding include GL13K [37]. However, limitations regarding the inadequate control of the orientation and structural conformation of these AMPs have led to the investigation of solid-binding peptide non-covalent immobilisation strategies. These offer the advantage of biomolecular self-assembly of the chimeric peptides onto various implant surfaces and also allows for easier manipulation of the AMP through a variety of biochemical techniques [185,194].

\subsection{Synthetic Mimics of AMPs as Antimicrobial Polymers}

The development of antimicrobial-peptide mimetic polymers is another effective strategy for overcoming the physiological instability of AMP molecules while reducing cytotoxicity towards mammalian cells. The copolymerization of AMPs with conventional polymers (such as polymethacrylates, polyacrylamides, polyamides and polycarbonates) via ring-opening polymerization produces amphiphilic antimicrobial polymers featuring both a cationic and hydrophobic side chain with contact-killing action [195,196]. In the development of AMP-mimetic amphiphilic polymers, it was noted that a high cationic charge and low hydrophobicity of the conventional polymer were critical design parameters for maintaining high bactericidal activity and low cytotoxicity [196]. A study investigating the antimicrobial properties of AMP HHC10 hybrid conjugates with polyphosphoesters, showed the reduction in cytotoxicity of the resulting polymer compared to the free 
AMP [197]. Therefore, AMP-mimetic polymers may offer the advantages of improved stability and maintenance of AMP antimicrobial activity, low cytotoxicity, ease of processing and manufacture of these rather costly compounds.

Zhou et al. synthesised peptide-mimetic alternating copolymers via copolymerization of $\varepsilon$-Z-lysine (cationic hydrophilic moiety) with hexamethylene diisocyanate (hydrophobic moiety). The resulting amphiphilic antibacterial polymer showed no cytotoxicity against mammalian cells and assisted bone repair [198]. This strategy could be evaluated for potential in hard tissue regeneration in periodontitis.

In a study by Takahashi and co-workers, the development of cationic amphiphilic methacrylate polymers via reversible addition-fragmentation chain transfer polymerization yielded polymers with bactericidal and biofilm inhibition activities through eradication of planktonic S. mutans bacteria [199]. Compared to chlorhexidine, these amphiphilic polymers displayed superior antimicrobial activity and similar cytotoxicity in human gingival fibroblasts and periodontal ligament stem cells [199].

In other studies, based on the same concept, researchers synthesised methacrylateended polypeptides via ring-opening polymerization of $\mathrm{N}$-carboxyanhydride (NCA) where UV irradiation with polydopamine (pDA) produced a brush-like polymer coating comprising cationic antimicrobial peptide and antifouling polysarcosine [200]. This AMP-based antimicrobial and antifouling polymer exhibited effective biocidal and antiadhesion activity against several bacterial strains and C. albicans over seven days yet maintained adequate biocompatibility in a mouse fibroblast cell line. The resulting dual-function polymer may be immobilised onto various types of biomaterials via the mussel-inspired pDA coating [200]. Another study used a similar approach for the fabrication of nano-structured star-shaped antimicrobial peptide polymers [201]. Although these materials were not developed specifically as dental materials, a similar approach could be investigated for dental applications as antimicrobial and antifouling coatings and nanomaterials.

\section{Conclusions and Future Considerations}

The design of antimicrobial and antifouling materials is highly focussed on the synthesis of direct dental restorative materials such as dental resin composites and adhesives. These constitute the most used materials in dental practice but due to their greater exposure to the microbes of the oral cavity, they are most susceptible to microbial colonization and attack.

Nanomaterials delivered in conjunction or loaded with antibiotics have gained considerable appeal in resins, endodontic sealers, coatings and short-term intra-pocket drugrelease systems for the treatment of periodontitis. The cytocompatibility of these systems may be easier to modulate via blending with bio-inert polymeric materials. In some cases, such as with tetracyclines, the released antimicrobial compound has the added benefit of host cell proliferation-a pertinent regenerative feature for the treatment of tissue loss in periodontitis.

Of the polymers with intrinsic antimicrobial and antifouling properties, QACs show promise for sufficient contact-killing action throughout the material bulk whilst maintaining adequate mechanical integrity. Its main challenge of cytotoxicity may be reduced by improving the strength of its covalent bonds to the resin to prevent leaching of monomers. Extensive cytocompatibility studies of leachable monomers in response to mechanical and chemical stresses in dental pulpal, gingival and fibroblastic cells as well as odontoblasts are still required. Within the same class of materials and gaining notable interest in clinical dentistry, are zwitterionic polymeric biocides. Their excellent biocompatibility holds potential for the development of dual function materials when combined with QACs - antimicrobial bactericidal action with antifouling anti-adhesion properties.

As an upcoming generation of new antimicrobial compounds, it is anticipated that AMPs will replace conventional antibiotics and antiseptics, such as chlorhexidine, in dental applications which are predisposed to antimicrobial resistance [184,190,202]. After addressing the key challenges of chemical and physical stability of AMPs in the oral cavity, 
these compounds may potentially be included in professionally applied treatments and daily homecare dental hygiene products such as toothpastes and mouthwashes.

Antimicrobial and antifouling resin composites, adhesives and coatings intended for long-term wear require extended periods of experimental profiling into the mechanical and chemical stability, biocompatibility and duration of antimicrobial activity. Such studies should be performed in response to prolonged exposure to the physiological and microbiological environment of the oral cavity, the daily activities and oral functions contributing to wear resistance and material life. This will assist in elucidating the performance of these materials in the clinical setting and thus paving the way for its implementation in patients. Properties of compressive strength, moisture sorption and bioerosion should be correlated to cytotoxicity as these factors may contribute to unintentional leaching of unreacted monomers. Experimental designs of future studies should allow for the use of tooth-restoration substrates with constant saliva flow to mimic the oral cavity and its daily wear and tear on these materials [203]. The effects of abrasion on surface properties of dental materials from daily activities of mastication and teeth brushing should also be studied. In addition, biofilm should be cultivated under a high cariogenic potential environment to simulate the use of the materials in caries positive patients. Another factor to consider, is the specific targeting of pathogenic microbial strains to maintain the population of beneficial commensals and a healthy oral microbiome. AMPs may be modified for specific targeting of $S$. mutans in carious lesions through incorporation of a non-specific bactericidal AMP and a targeting moiety consisting of a species-specific, high-affinity binding peptide, such as the $S$. mutans produced pheromone [204]. An alternative strategy investigates the use of narrow-spectrum small molecules (3F1) for specific targeting of S. mutans [205].

The emerging trend of multifunctional biomaterials featuring a combination of antimicrobial, antifouling, remineralizing or regenerative properties with microbial specific targeting holds promise for the design of clinically effective dental materials with lowcytotoxic profiles and scalable manufacture for controlling pathogens in the oral cavity and extending the life of dental restorations.

Author Contributions: Conceptualization, P.R.; investigation, P.R., N.A.P., A.D., R.Z.A., S.D. and M.A.; writing—original draft preparation, P.R., N.A.P., R.Z.A. and A.D.; writing-review and editing, P.R., S.D. and M.A.; funding acquisition, A.D. and P.R. All authors have read and agreed to the published version of the manuscript.

Funding: A.D. acknowledges funding from the Fogarty International Center of the National Institutes of Health under Award Number K43TW010371. The content is solely the responsibility of the author and does not necessarily represent the official views of the National Institutes of Health.This work was supported by the National Research Foundation (NRF) of South Africa (Grant no. 129890) awarded to P.R.

Institutional Review Board Statement: Not applicable.

Informed Consent Statement: Not applicable.

Conflicts of Interest: The authors declare no conflict of interest.

\section{References}

1. Bernabe, E.; Marcenes, W.; Hernandez, C.R.; Bailey, J.; Abreu, L.G.; Alipour, V.; Amini, S.; Arabloo, J.; Arefi, Z.; Arora, A.; et al. Global, Regional, and National Levels and Trends in Burden of Oral Conditions from 1990 to 2017: A Systematic Analysis for the Global Burden of Disease 2017 Study. J. Dent. Res. 2020, 99, 362-373.

2. Deo, P.N.; Deshmukh, R. Oral Microbiome: Unveiling the Fundamentals. J. Oral Maxillofac. Pathol. 2019, 23, 122-128.

3. Gao, L.; Xu, T.; Huang, G.; Jiang, S.; Gu, Y.; Chen, F. Oral Microbiomes: More and More Importance in Oral Cavity and Whole Body. Protein Cell 2018, 9, 488-500. [CrossRef] [PubMed]

4. Hyde, S.; Dupuis, V.; Mariri, B.P.; Dartevelle, S. Prevention of Tooth Loss and Dental Pain for Reducing the Global Burden of Oral Diseases. Int. Dent. J. 2017, 67, 19-25. [CrossRef]

5. Ma, L.; Wang, Y.; Wang, M.; Tian, Y.; Kang, W.; Liu, H.; Wang, H.; Dou, J.; Zhou, C. Effective Antimicrobial Activity of Cbf-14, Derived from a Cathelin-like Domain, against Penicillin-Resistant Bacteria. Biomaterials 2016, 87, 32-45. [CrossRef] [PubMed] 
6. Oberoi, S.S.; Dhingra, C.; Sharma, G.; Sardana, D. Antibiotics in Dental Practice: How Justified Are We. Int. Dent. J. 2014, 65, 4-10. [CrossRef] [PubMed]

7. Anusavice, K.J. Present and Future Approaches for the Control of Caries. J. Dent. Educ. 2005, 69, 538-554. [CrossRef] [PubMed]

8. TOBIAS, R.S. Antibacterial Properties of Dental Restorative Materials: A Review. Int. Endod. J. 1988, 21, 155-160. [CrossRef]

9. Jandt, K.D.; Sigusch, B.W. Future Perspectives of Resin-Based Dental Materials. Dent. Mater. 2009, 25, 1001-1006. [CrossRef] [PubMed]

10. Imazato, S.; Russell, R.R.B.; McCabe, J.F. Antibacterial Activity of MDPB Polymer Incorporated in Dental Resin. J. Dent. 1995, 23, 177-181. [CrossRef]

11. Pinto, C.; Berger, S.; Cavalli, V.; Da Cruz, S.; Goncalves, R.; Ambrosano, G.; Giannini, M. In Situ Antimicrobial Activity and Inhibition of Secondary Caries of Self-Etching Adhesives Containing an Antibacterial Agent and/or Fluoride. Am. J. Dent. 2015, 28, 167-173.

12. Thongthai, P.; Kitagawa, H.; Kitagawa, R.; Hirose, N.; Noree, S.; Iwasaki, Y.; Imazato, S. Development of Novel Surface Coating Composed of MDPB and MPC with Dual Functionality of Antibacterial Activity and Protein Repellency. J. Biomed. Mater. Res. Part B Appl. Biomater. 2020, 108, 3241-3249. [CrossRef]

13. Zhang, J.F.; Wu, R.; Fan, Y.; Liao, S.; Wang, Y.; Wen, Z.T.; Xu, X. Antibacterial Dental Composites with Chlorhexidine and Mesoporous Silica. J. Dent. Res. 2014, 93, 1283-1289. [CrossRef]

14. Zafar, M.S.; Ullah, R.; Qamar, Z.; Fareed, M.A.; Amin, F.; Khurshid, Z.; Sefat, F. Properties of dental biomaterials. In Advanced Dental Biomaterials; Woodhead Publishing: Sawston, UK, 2019; pp. 7-35.

15. Korkut, E.; Torlak, E.; Altunsoy, M. Antimicrobial and Mechanical Properties of Dental Resin Composite Containing Bioactive Glass. J. Appl. Biomater. Funct. Mater. 2016, 14, e296-e301. [CrossRef] [PubMed]

16. Al Sunbul, H.; Silikas, N.; Watts, D.C. Surface and Bulk Properties of Dental Resin- Composites after Solvent Storage. Dent. Mater 2016, 32, 987-997. [CrossRef] [PubMed]

17. Ibrahim, M.; El-Wassefy, N.; Farahat, D. Biocompatibility of Dental Biomaterials. In Biomaterials for Oral and Dental Tissue Engineering; Tayebi, L., Moharamzadeh, K., Eds.; Woodhead Publishing: Sawston, UK, 2017; pp. 117-140.

18. Rajan, G.; Shouha, P.; Ellakwa, A.; Bhowmik, K.; Xi, J.; Prusty, G. Evaluation of the Physical Properties of Dental Resin Composites Using Optical Fiber Sensing Technology. Dent. Mater. 2016, 32, 1113-1123. [CrossRef]

19. Wu, T.; Gan, X.; Zhu, Z.; Yu, H. Aging Effect of PH on the Mechanical and Tribological Properties of Dental Composite Resins. Part. Sci. Technol. 2018, 36, 378-385. [CrossRef]

20. Aliabadi, E.; Tavanafar, S.; Khaghaninejad, M.S. Marginal Bone Resorption of Posterior Mandible Dental Implants with Different Insertion Methods. BMC Oral Health 2020, 20, 1-7. [CrossRef] [PubMed]

21. Zhang, L.; Weir, M.D.; Chow, L.C.; Antonucci, J.M.; Chen, J.; Xu, H.H.K. Novel Rechargeable Calcium Phosphate Dental Nanocomposite. Dent. Mater. 2016, 32, 285-293. [CrossRef] [PubMed]

22. Zhang, T.; Wang, Z.; Hancock, R.E.W.; De La Fuente-Núñez, C.; Haapasalo, M. Treatment of Oral Biofilms by a D-Enantiomeric Peptide. PLoS ONE 2016, 11, e0166997. [CrossRef]

23. Al-Dulaijan, Y.A.; Weir, M.D.; Melo, M.A.S.; Sun, J.; Oates, T.W.; Zhang, K.; Xu, H.H.K. Protein-Repellent Nanocomposite with Rechargeable Calcium and Phosphate for Long-Term Ion Release. Dent. Mater. 2018, 34, 1735-1747. [CrossRef] [PubMed]

24. Al-Qarni, F.D.; Tay, F.; Weir, M.D.; Melo, M.A.S.; Sun, J.; Oates, T.W.; Xie, X.; Xu, H.H.K. Protein-Repelling Adhesive Resin Containing Calcium Phosphate Nanoparticles with Repeated Ion-Recharge and Re-Releases. J. Dent. 2018, 78, 91-99. [CrossRef] [PubMed]

25. Yuan, Y.; Hays, M.P.; Hardwidge, P.R.; Kim, J. Surface Characteristics Influencing Bacterial Adhesion to Polymeric Substrates. RSC Adv. 2017, 7, 14254-14261. [CrossRef]

26. De-la-Pinta, I.; Cobos, M.; Ibarretxe, J.; Montoya, E.; Eraso, E.; Guraya, T.; Quindós, G. Effect of Biomaterials Hydrophobicity and Roughness on Biofilm Development. J. Mater. Sci. Mater. Med. 2019, 30, 77-88. [CrossRef]

27. Ahi, Z.B.; Renkler, N.Z.; Gul Seker, M.; Tuzlakoglu, K. Biodegradable Polymer Films with a Natural Antibacterial Extract as Novel Periodontal Barrier Membranes. Int. J. Biomater. 2019, 2019, 7932470. [CrossRef] [PubMed]

28. Rezaie, H.; Rizi, H.; Khamseh, M.; Ochsner, A. A Review on Dental Materials; Springer: Berlin/Heidelberg, Germany, 2020.

29. Øilo, M.; Bakken, V. Biofilm and Dental Biomaterials. Materials 2015, 8, 2887-2900. [CrossRef]

30. Hao, Y.; Huang, X.; Zhou, X.; Li, M.; Ren, B.; Peng, X.; Cheng, L. Influence of Dental Prosthesis and Restorative Materials Interface on Oral Biofilms. Int. J. Mol. Sci. 2018, 19, 3157. [CrossRef]

31. Farrugia, C.; Haider, J.; Camilleri, L.; Camilleri, J. Clinical Relevance of Antimicrobial Testing Results for Dental Restorative Materials. J. Appl. Biomater. Funct. Mater. 2017, 15, 153-161. [CrossRef]

32. Qiu, W.; Zhou, Y.; Li, Z.; Huang, T.; Xiao, Y.; Cheng, L.; Peng, X.; Zhang, L.; Ren, B. Application of Antibiotics/Antimicrobial Agents on Dental Caries. Biomed. Res. Int. 2020, 2020, 5658212. [CrossRef]

33. Sumi, Y.; Miura, H.; Sunakawa, M.; Michiwaki, Y.; Sakagami, N. Colonization of Dental Plaque by Respiratory Pathogens in Dependent Elderly. Gerodontology 2002, 19, 25-29. [CrossRef] [PubMed]

34. Li, L.; Finnegan, M.B.; Özkan, S.; Kim, Y.; Lillehoj, P.B.; Ho, C.M.; Lux, R.; Mito, R.; Loewy, Z.; Shi, W. In Vitro Study of Biofilm Formation and Effectiveness of Antimicrobial Treatment on Various Dental Material Surfaces. Mol. Oral Microbiol. 2010, 25, 384-390. [CrossRef] [PubMed] 
35. Beldüz, N.; Kamburoğlu, A.; Yilmaz, Y.; Tosun, I.; Beldüz, M.; Kara, C. Evaluation of Candida Albicans Biofilm Formation on Various Dental Restorative Material Surfaces. Niger. J. Clin. Pract. 2017, 20, 355-360. [CrossRef] [PubMed]

36. Asai, D.; Nakashima, H. Pathogenic Viruses Commonly Present in the Oral Cavity and Relevant Antiviral Compounds Derived from Natural Products. Medicines 2018, 5, 120. [CrossRef] [PubMed]

37. Jiao, Y.; Tay, F.R.; Niu, L.N.; Chen, J.H. Advancing Antimicrobial Strategies for Managing Oral Biofilm Infections. Int. J. Oral Sci. 2019, 11, 1-11. [CrossRef] [PubMed]

38. Rimondini, L.; Cochis, A.; Varoni, E.; Azzimonti, B.; Carrassi, A. Biofilm Formation on Implants and Prosthetic Dental Materials. In Handbook of Bioceramics and Biocomposites, 1st ed.; Antoniac, I.V., Ed.; Springer International Publishing: Cham, Switzerland, 2015; pp. 1-37.

39. Lad, P.P.; Kamath, M.; Tarale, K.; Kusugal, P.B. Practical Clinical Considerations of Luting Cements: A Review. J. Int. Oral Health JIOH 2014, 6, 116-120.

40. Ferrando-Magraner, E.; Bellot-Arcis, C.; Paredes-Gallardo, V.; Almerich-Silla, J.M.; Garcia-Sanz, V.; Fernandez-Alonso, M.; Montiel-Company, J.M. Antibacterial Properties of Nanoparticles in Dental Restorative Materials. A Systematic Review and Meta-Analysis. Medicina 2020, 56, 55. [CrossRef]

41. Daugela, P.; Oziunas, R.; Zekonis, G. Antibacterial Potential of Contemporary Dental Luting Cements. Stomatologija 2008, 10, 16-21.

42. Magalhães, A.P.R.; Moreira, F.C.L.; Alves, D.R.S.; Estrela, C.R.A.; Estrela, C.; Carrião, M.S.; Bakuzis, A.F.; Lopes, L.G. Silver Nanoparticles in Resin Luting Cements: Antibacterial and Physiochemical Properties. J. Clin. Exp. Dent. 2016, 18, 415-422. [CrossRef]

43. Andrade, V.; Martínez, A.; Rojas, N.; Bello-Toledo, H.; Flores, P.; Sánchez-Sanhueza, G.; Catalán, A. Antibacterial Activity against Streptococcus Mutans and Diametrical Tensile Strength of an Interim Cement Modified with Zinc Oxide Nanoparticles and Terpenes: An in Vitro Study. J. Prosthet. Dent. 2018, 119, 862.e1-862.e7. [CrossRef]

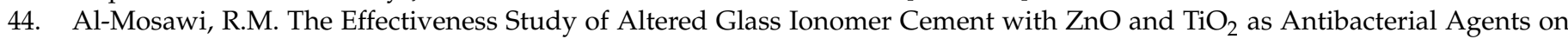
Microbial of Mouth. Trends Pharm. Nanotechnol. 2020, 2, 52-58. [CrossRef]

45. Mokhtari, S.; Skelly, K.D.; Krull, E.A.; Coughlan, A.; Mellott, N.P.; Gong, Y.; Borges, R.; Wren, A.W. Copper-Containing Glass Polyalkenoate Cements Based on SiO2-ZnO-CaO-SrO-P2O5 Glasses: Glass Characterization, Physical and Antibacterial Properties. J. Mater. Sci. 2017, 52, 8886-8903. [CrossRef]

46. Wassmann, T.; Schubert, A.; Malinski, F.; Rosentritt, M.; Krohn, S.; Techmer, K.; Bürgers, R. The Antimicrobial and Cytotoxic Effects of a Copper-Loaded Zinc Oxide Phosphate Cement. Clin. Oral Investig. 2020, 24, 3899-3909. [CrossRef]

47. Tuncdemir, M.; Ugur, A.; Ozdemir, B. Antimicrobial Activity of Glass Ionomer Cements with Chlorhexidine and Propolis: An In Vitro Study. Pediatr. Infect. Dis. J. 2019, 14, 168-170. [CrossRef]

48. Alsahafi, R.; Balhaddad, A.A.; Mitwalli, H.; Ibrahim, M.S.; Melo, M.A.S.; Oates, T.W.; Xu, H.H.K.; Weir, M.D. Novel Crown Cement Containing Antibacterial Monomer and Calcium Phosphate Nanoparticles. Nanomaterials 2020, 10, 2001. [CrossRef]

49. Boutsiouki, C.; Frankenberger, R.; Lücker, S.; Krämer, N. Inhibition of Secondary Caries in Vitro by Addition of Chlorhexidine to Adhesive Components. Dent. Mater. 2019, 35, 422-433. [CrossRef]

50. Cagna, D.R.; Donovan, T.E.; McKee, J.R.; Eichmiller, F.; Metz, J.E.; Albouy, J.P.; Marzola, R.; Murphy, K.R.; Troeltzsch, M. Annual Review of Selected Scientific Literature: A Report of the Committee on Scientific Investigation of the American Academy of Restorative Dentistry. J. Prosthet. Dent. 2019, 122, 198-269. [CrossRef]

51. Nedeljkovic, I.; Teughels, W.; De Munck, J.; Van Meerbeek, B.; Van Landuyt, K.L. Is Secondary Caries with Composites a Material-Based Problem? Dent. Mater. 2015, 31, e247-e277. [CrossRef]

52. Chen, S.; Yang, J.; Jia, Y.G.; Lu, B.; Ren, L. A Study of 3D-Printable Reinforced Composite Resin: PMMA Modified with Silver Nanoparticles Loaded Cellulose Nanocrystal. Materials 2018, 11, 2444. [CrossRef] [PubMed]

53. André, C.B.; Chan, D.C.; Giannini, M. Antibacterial-Containing Dental Adhesives' Effects on Oral Pathogens and on Streptococcus Mutans Biofilm: Current Perspectives. Am. J. Dent. 2018, 31, 37B-41B. [PubMed]

54. Chatzistavrou, X.; Lefkelidou, A.; Papadopoulou, L.; Pavlidou, E.; Paraskevopoulos, K.M.; Christopher Fenno, J.; Flannagan, S.; González-Cabezas, C.; Kotsanos, N.; Papagerakis, P. Bactericidal and Bioactive Dental Composites. Front. Physiol. 2018, 9, 1-11. [CrossRef]

55. Imazato, S.; Ebi, N.; Tarumi, H.; Russell, R.R.B.; Kaneko, T.; Ebisu, S. Bactericidal Activity and Cytotoxicity of Antibacterial Monomer MDPB. Biomaterials 1999, 20, 899-903. [CrossRef]

56. Nishida, M.; Imazato, S.; Takahashi, Y.; Ebisu, S.; Ishimoto, T.; Nakano, T.; Yasuda, Y.; Saito, T. The Influence of the Antibacterial Monomer 12-Methacryloyloxydodecylpyridinium Bromide on the Proliferation, Differentiation and Mineralization of Odontoblast-like Cells. Biomaterials 2010, 31, 1518-1532. [CrossRef] [PubMed]

57. Imazato, S.; Chen, J.; Ma, S.; Izutani, N.; Li, F. Antibacterial Resin Monomers Based on Quaternary Ammonium and Their Benefits in Restorative Dentistry. Jpn. Dent. Sci. Rev. 2012, 48, 115-125. [CrossRef]

58. André, C.B.; Gomes, B.P.F.A.; Duque, T.M.; Stipp, R.N.; Chan, D.C.N.; Ambrosano, G.M.B.; Giannini, M. Dentine Bond Strength and Antimicrobial Activity Evaluation of Adhesive Systems. J. Dent. 2015, 43, 466-475. [CrossRef] [PubMed]

59. Fugolin, A.P.P.; Pfeifer, C.S. New Resins for Dental Composites. J. Dent. Res. 2017, 96, 1085-1091. [CrossRef] [PubMed]

60. Kashi, A.; Saha, S. Evidence-Based Techniques to Assess the Performance of Dental Implants. J. Oral Implantol. 2013, 39, 655-661. [CrossRef] [PubMed] 
61. Hickok, N.J.; Shapiro, I.M.; Chen, A.F. The Impact of Incorporating Antimicrobials into Implant Surfaces. J. Dent. Res. 2018, 97, 14-22. [CrossRef]

62. Sadig, W. The Denture Hygiene, Denture Stomatitis and Role of Dental Hygienist. Int. J. Dent. Hyg. 2009, 227-231. [CrossRef]

63. Gendreau, L.; Loewy, Z.G. Epidemiology and Etiology of Denture Stomatitis. J. Prosthodont. 2011, 20, 251-260. [CrossRef]

64. Mirizadeh, A.; Atai, M.; Ebrahimi, S. Fabrication of Denture Base Materials with Antimicrobial Properties. J. Prosthet. Dent. 2018, 119, 292-298. [CrossRef]

65. Poggio, C.; Trovati, F.; Ceci, M.; Chiesa, M.; Colombo, M.; Pietrocola, G. Biological and Antibacterial Properties of a New Silver Fiber Post: In Vitro Evaluation. J. Clin. Exp. Dent. 2017, 9, e387-e393. [CrossRef] [PubMed]

66. AlShwaimi, E.; Bogari, D.; Ajaj, R.; Al-Shahrani, S.; Almas, K.; Majeed, A. In Vitro Antimicrobial Effectiveness of Root Canal Sealers against Enterococcus Faecalis: A Systematic Review. J. Endod. 2016, 42, 1588-1597. [CrossRef] [PubMed]

67. Shrestha, A.; Kishen, A. Antibacterial Nanoparticles in Endodontics: A Review. J. Endod. 2016, 42, 1417-1426. [CrossRef]

68. Trichês, K.M.; Júnior, J.S.; Calixto, J.B.; Machado, R.; Rosa, T.P.; Silva, E.J.N.L.; Vansan, L.P. Connective Tissue Reaction of Rats to a New Zinc-Oxide-Eugenol Endodontic Sealer. Microsc. Res. Tech. 2013, 76, 1292-1296. [CrossRef]

69. Kapralos, V.; Koutroulis, A.; Ørstavik, D.; Sunde, P.T.; Rukke, H.V. Antibacterial Activity of Endodontic Sealers against Planktonic Bacteria and Bacteria in Biofilms. J. Endod. 2018, 44, 149-154. [CrossRef]

70. Zhang, H.; Shen, Y.; Ruse, N.D.; Haapasalo, M. Antibacterial Activity of Endodontic Sealers by Modified Direct Contact Test Against Enterococcus Faecalis. J. Endod. 2009, 35, 1051-1055. [CrossRef] [PubMed]

71. Nasajpour, A.; Ansari, S.; Rinoldi, C.; Rad, A.S.; Aghaloo, T.; Shin, S.R.; Mishra, Y.K.; Adelung, R.; Swieszkowski, W.; Annabi, N.; et al. A Multifunctional Polymeric Periodontal Membrane with Osteogenic and Antibacterial Characteristics. Adv. Funct. Mater. 2018, 28, 1-8. [CrossRef]

72. Listgarten, M.A. Pathogenesis of Periodontitis. J. Clin. Periodontol. 1986, 13, 418-425. [CrossRef]

73. Kinane, D.F.; Stathopoulou, P.G.; Papapanou, P.N. Periodontal Diseases. Nat. Rev. Dis. Prim. 2017, 3, 1-14. [CrossRef]

74. Madhumathi, K.; Sampath Kumar, T.S. Regenerative Potential and Anti-Bacterial Activity of Tetracycline Loaded Apatitic Nanocarriers for the Treatment of Periodontitis. Biomed. Mater. 2014, 9, 035002. [CrossRef]

75. Joshi, D.; Garg, T.; Goyal, A.K.; Rath, G. Advanced Drug Delivery Approaches Against Periodontitis. Drug Deliv. 2016, 23 , 363-377. [CrossRef] [PubMed]

76. Chi, M.; Qi, M.; Wang, P.; Weir, M.D.; Melo, M.A.; Sun, X.; Dong, B.; Li, C.; Wu, J.; Wang, L.; et al. Novel Bioactive and Therapeutic Dental Polymeric Materials to Inhibit Periodontal Pathogens and Biofilms. Int. J. Mol. Sci. 2019, 20, 278. [CrossRef] [PubMed]

77. Shahi, R.G.; Albuquerque, M.T.P.; Münchow, E.A.; Blanchard, S.B.; Gregory, R.L.; Bottino, M.C. Novel Bioactive TetracyclineContaining Electrospun Polymer Fibers as a Potential Antibacterial Dental Implant Coating. Odontology 2017, 105, 354-363. [CrossRef]

78. Leung, D.; Spratt, D.A.; Pratten, J.; Gulabivala, K.; Mordan, N.J.; Young, A.M. Chlorhexidine-Releasing Methacrylate Dental Composite Materials. Biomaterials 2005, 26, 7145-7153. [CrossRef]

79. Karacan, I.; Macha, I.J.; Choi, G.; Cazalbou, S.; Ben-Nissan, B. Antibiotic Containing Poly Lactic Acid/Hydroxyapatite Biocomposite Coatings for Dental Implant Applications. Key Eng. Mater. 2017, 758, 120-125. [CrossRef]

80. Cuppini, M.; Zatta, K.C.; Mestieri, L.B.; Grecca, F.S.; Leitune, V.C.B.; Guterres, S.S.; Collares, F.M. Antimicrobial and AntiInflammatory Drug-Delivery Systems at Endodontic Reparative Material: Synthesis and Characterization. Dent. Mater. 2019, 35 457-467. [CrossRef]

81. Stewart, C.A.; Hong, J.H.; Hatton, B.D.; Finer, Y. Antimicrobial Antidegradative Dental Adhesive Preserves Restoration-Tooth Bond. Dent. Mater. 2020, 36, 1666-1679. [CrossRef] [PubMed]

82. Mai, H.N.; Kim, D.Y.; Hyun, D.C.; Park, J.H.; Lee, S.M.; Lee, D.H. A New Antibacterial Agent-Releasing Polydimethylsiloxane Coating for Polymethyl Methacrylate Dental Restorations. J. Clin. Med. 2019, 8, 1831. [CrossRef] [PubMed]

83. Wyganowska-Swiatkowska, M.; Kotwicka, M.; Urbaniak, P.; Nowak, A.; Skrzypczak-Jankun, E.; Jankun, J. Clinical Implications of The Growth-Suppressive Effects of Chlorhexidine at Low and High Concentrations on Human Gingival Fibroblasts and Changes in Morphology. Int. J. Mol. Med. 2016, 37, 1594-1600. [CrossRef] [PubMed]

84. Coelho, A.S.; Laranjo, M.; Gonçalves, A.C.; Paula, A.; Paulo, S.; Abrantes, A.M.; Caramelo, F.; Ferreira, M.M.; Silva, M.J.; Carrilho, E.; et al. Cytotoxic Effects of a Chlorhexidine Mouthwash and of an Enzymatic Mouthwash on Human Gingival Fibroblasts. Odontology 2020, 108, 260-270. [CrossRef]

85. Wood, N.J.; Jenkinson, H.F.; Davis, S.A.; Mann, S.; O'Sullivan, D.J.; Barbour, M.E. Chlorhexidine Hexametaphosphate Nanoparticles as a Novel Antimicrobial Coating for Dental Implants. J. Mater. Sci. Mater. Med. 2015, 26, 1-10. [CrossRef] [PubMed]

86. Garner, S.; Barbour, M.E. Nanoparticles for Controlled Delivery and Sustained Release of Chlorhexidine in the Oral Environment. Oral Dis. 2015, 21, 641-644. [CrossRef] [PubMed]

87. Fullriede, H.; Abendroth, P.; Ehlert, N.; Doll, K.; Schäske, J.; Winkel, A.; Stumpp, S.N.; Stiesch, M.; Behrens, P. PH-Responsive Release of Chlorhexidine from Modified Nanoporous Silica Nanoparticles for Dental Applications. BioNanoMaterials 2016, 17, 59-72. [CrossRef]

88. Priyadarshini, B.M.; Selvan, S.T.; Lu, T.B.; Xie, H.; Neo, J.; Fawzy, A.S. Chlorhexidine Nanocapsule Drug Delivery Approach to the Resin-Dentin Interface. J. Dent. Res. 2016, 95, 1065-1072. [CrossRef]

89. Priyadarshini, B.M.; Mitali, K.; Lu, T.B.; Handral, H.K.; Dubey, N.; Fawzy, A.S. PLGA Nanoparticles as Chlorhexidine-Delivery Carrier to Resin-Dentin Adhesive Interface. Dent. Mater. 2017, 33, 830-846. [CrossRef] 
90. Luo, D.; Shahid, S.; Hasan, S.M.; Whiley, R.; Sukhorukov, G.B.; Cattell, M.J. Controlled Release of Chlorhexidine from a HEMA-UDMA Resin Using a Magnetic Field. Dent. Mater. 2018, 34, 764-775. [CrossRef]

91. Luo, D.; Shahid, S.; Sukhorukov, G.B.; Cattell, M.J. Synthesis of Novel Chlorhexidine Spheres with Controlled Release from a UDMA-HEMA Resin Using Ultrasound. Dent. Mater. 2017, 33, 713-722. [CrossRef] [PubMed]

92. Boaro, L.C.C.; Campos, L.M.; Varca, G.H.C.; dos Santos, T.M.R.; Marques, P.A.; Sugii, M.M.; Saldanha, N.R.; Cogo-Müller, K.; Brandt, W.C.; Braga, R.R.; et al. Antibacterial Resin-Based Composite Containing Chlorhexidine for Dental Applications. Dent. Mater. 2019, 35, 909-918. [CrossRef]

93. Bottino, M.C.; Münchow, E.A.; Albuquerque, M.T.P.; Kamocki, K.; Shahi, R.; Gregory, R.L.; Chu, T.M.G.; Pankajakshan, D. Tetracycline-Incorporated Polymer Nanofibers as a Potential Dental Implant Surface Modifier. J. Biomed. Mater. Res. Part B Appl. Biomater. 2017, 105, 2085-2092. [CrossRef]

94. Tondnevis, F.; Ketabi, M.; Fekrazad, R.; Sadeghi, A.; Keshvari, H.; Abolhasani, M. In Vitro Characterization of PolyurethaneCarbon Nanotube Drug Eluting Composite Scaffold for Dental Tissue Engineering Application. J. Biomim. Biomater. Biomed. Eng. 2020, 47, 13-24. [CrossRef]

95. De Avila, E.D.; Castro, A.G.B.; Tagit, O.; Krom, B.P.; Löwik, D.; van Well, A.A.; Bannenberg, L.J.; Vergani, C.E.; van den Beucken, J.J.J.P. Anti-Bacterial Efficacy via Drug-Delivery System from Layer-by-Layer Coating for Percutaneous Dental Implant Components. Appl. Surf. Sci. 2019, 488, 194-204. [CrossRef]

96. Potočnik, J. Commission Recommendation of 18 October 2011 on the Definition of Nanomaterial. Off. J. Eur. Union 2011, L275, 38-40.

97. Dube, A. Nanomedicines for Infectious Diseases. Pharm. Res. 2019, 36, 10-11. [CrossRef] [PubMed]

98. Dube, A.; Reynolds, J.L.; Law, W.C.; Maponga, C.C.; Prasad, P.N.; Morse, G.D. Multimodal Nanoparticles That Provide Immunomodulation and Intracellular Drug Delivery for Infectious Diseases. Nanomed. Nanotechnol. Biol. Med. 2014, 10, 831-838. [CrossRef] [PubMed]

99. Holay, M.; Guo, Z.; Pihl, J.; Heo, J.; Park, J.H.; Fang, R.H.; Zhang, L. Bacteria-Inspired Nanomedicine. ACS Appl. Bio Mater. 2020. [CrossRef]

100. Kumar, L.; Verma, S.; Vaidya, B.; Gupta, V. Bioadhesive Polymers for Targeted Drug Delivery. In Nanotechnology-Based Approaches for Targeting and Delivery of Drugs and Genes; Academic Press: Cambridge, UK, 2017; pp. 322-362.

101. Ghafar, H.; Khan, M.I.; Sarwar, H.S.; Yaqoob, S.; Hussain, S.Z.; Tariq, I.; Madni, A.U.; Shahnaz, G.; Sohail, M.F. Development and Characterization of Bioadhesive Film Embedded with Lignocaine and Calcium Fluoride Nanoparticles. AAPS PharmSciTech 2020, 21, 1-12. [CrossRef]

102. Mahmoud, M.Y.; Steinbach-Rankins, J.M.; Demuth, D.R. Functional Assessment of Peptide-Modified PLGA Nanoparticles against Oral Biofilms in a Murine Model of Periodontitis. J. Control. Release 2019, 297, 3-13. [CrossRef]

103. Zięba, M.; Chaber, P.; Duale, K.; Maksymiak, M.M.; Basczok, M.; Kowalczuk, M.; Adamus, G. Polymeric Carriers for Delivery Systems in the Treatment of Chronic Periodontal Disease. Polymers 2020, 12, 1574. [CrossRef]

104. Sánchez-López, E.; Gomes, D.; Esteruelas, G.; Bonilla, L.; Lopez-Machado, A.L.; Galindo, R.; Cano, A.; Espina, M.; Ettcheto, M.; Camins, A.; et al. Metal-Based Nanoparticles as Antimicrobial Agents: An Overview. Nanomaterials 2020, 10, 292. [CrossRef] [PubMed]

105. Neel, E.A.A.; Bozec, L.; Perez, R.A.; Kim, H.W.; Knowles, J.C. Nanotechnology in Dentistry: Prevention, Diagnosis, and Therapy. Int. J. Nanomed. 2015, 10, 6371-6394. [CrossRef] [PubMed]

106. Noronha, V.T.; Paula, A.J.; Durán, G.; Galembeck, A.; Cogo-Müller, K.; Franz-Montan, M.; Durán, N. Silver Nanoparticles in Dentistry. Dent. Mater. 2017, 33, 1110-1126. [CrossRef] [PubMed]

107. Carrouel, F.; Viennot, S.; Ottolenghi, L.; Gaillard, C.; Bourgeois, D. Nanoparticles as Anti-Microbial, Anti-Inflammatory, and Remineralizing Agents in Oral Care Cosmetics: A Review of the Current Situation. Nanomaterials 2020, 10, 140. [CrossRef]

108. Fasiku (Oluwaseun), V.; Omolo, C.A.; Govender, T. Free Radical-Releasing Systems for Targeting Biofilms. J. Control. Release 2020, 322, 248-273. [CrossRef]

109. Hernández-Sierra, J.F.; Galicia-Cruz, O.; Salinas-Acosta, A.; Ruíz, F.; Pierdant-Pérez, M.; Pozos-Guillén, A. In Vitro Cytotoxicity of Silver Nanoparticles on Human Periodontal Fibroblasts. J. Clin. Pediatric Dent. 2011, 36, 37-42. [CrossRef]

110. Antunes, E.; Mmola, M.; Meyer, M.; Beukes, D. Assessment of the Bactericidal Effect of Green Synthesized Silver Nanoparticles against a Panel of Infectious Microorganisms. Planta Med. 2016, 81, S1-S381. [CrossRef]

111. Majoumouo, M.S.; Sibuyi, N.R.S.; Tincho, M.B.; Mbekou, M.; Boyom, F.F.; Meyer, M. Enhanced Anti-Bacterial Activity of Biogenic Silver Nanoparticles Synthesized from Terminalia Mantaly Extracts. Int. J. Nanomed. 2019, 14, 9031-9046. [CrossRef] [PubMed]

112. Feroze, N.; Arshad, B.; Younas, M.; Afridi, M.I.; Saqib, S.; Asma, A. Fungal Mediated Synthesis of Silver Nanoparticles and Evaluation of Antibacterial Activity. Microsc. Res. Tech. 2019, 1-9. [CrossRef]

113. Jyoti, K.; Arora, D.; Fekete, G.; Lendvai, L.; Dogossy, G.; Singh, T. Antibacterial and Anti-Inflammatory Activities of Cassia Fistula Fungal Broth-Capped Silver Nanoparticles. Mater. Technol. 2020, 1-11. [CrossRef]

114. Noor, S.; Shah, Z.; Javed, A.; Ali, A.; Hussain, S.B.; Zafar, S.; Ali, H.; Muhammad, S.A. A Fungal Based Synthesis Method for Copper Nanoparticles with the Determination of Anticancer, Antidiabetic and Antibacterial Activities. J. Microbiol. Methods 2020, 174, 105966. [CrossRef] 
115. Halkai, K.R.; Halkai, R.; Mudda, J.A.; Shivanna, V.; Rathod, V. Clinical Evaluation of Self-adhering Flowable Composite versus Conventional Flowable Composite in Conservative Class I Cavities: Randomized Controlled Trial. J. Conserv. Dent. 2018, 21, 485-490.

116. Halkai, K.R.; Mudda, J.A.; Shivanna, V.; Patil, V.; Rathod, V.; Halkai, R. Cytotoxicity Evaluation of Fungal-Derived Silver Nanoparticles on Human Gingival Fibroblast Cell Line: An in Vitro Study. J. Conserv. Dent. 2019, 22, 160-163. [CrossRef] [PubMed]

117. Tokajuk, G.; Niemirowicz, K.; Deptuła, P.; Piktel, E.; Cieśluk, M.; Wilczewska, A.Z.; Dąbrowski, J.R.; Bucki, R. Use of Magnetic Nanoparticles as a Drug Delivery System to Improve Chlorhexidine Antimicrobial Activity. Int. J. Nanomed. 2017, 12, 7833-7846. [CrossRef]

118. Das, P.; Karankar, V.S. New Avenues of Controlling Microbial Infections through Anti-Microbial and Anti-Biofilm Potentials of Green Mono-and Multi-Metallic Nanoparticles: A Review. J. Microbiol. Methods 2019, 167, 105766. [CrossRef]

119. Holden, M.S.; Black, J.; Lewis, A.; Boutrin, M.-C.; Walemba, E.; Sabir, T.S.; Boskovic, D.S.; Wilson, A.; Fletcher, H.M.; Perry, C.C. Antibacterial Activity of Partially Oxidized Ag/Au Nanoparticles against the Oral Pathogen Porphyromonas Gingivalis W83. J. Nanomater. 2016, 2016, 9605906. [CrossRef]

120. Cao, W.; Zhang, Y.; Wang, X.; Chen, Y.; Li, Q.; Xing, X.; Xiao, Y.; Peng, X.; Ye, Z. Development of a Novel Resin-Based Dental Material with Dual Biocidal Modes and Sustained Release of Ag+ Ions Based on Photocurable Core-Shell AgBr/Cationic Polymer Nanocomposites. J. Mater. Sci. Mater. Med. 2017, 28, 103-114. [CrossRef]

121. Baras, B.H.; Wang, S.; Melo, M.A.S.; Tay, F.; Fouad, A.F.; Arola, D.D.; Weir, M.D.; Xu, H.H.K. Novel Bioactive Root Canal Sealer with Antibiofilm and Remineralization Properties. J. Dent. 2019, 83, 67-76. [CrossRef] [PubMed]

122. Jiang, T.; James, R.; Kumbar, S.G.; Laurencin, C.T. Chitosan as a Biomaterial: Structure, Properties, and Applications in Tissue Engineering and Drug Delivery. Nat. Synth. Biomed. Polym. 2014, 91-113. [CrossRef]

123. Beg, S.; Dhiman, S.; Sharma, T.; Jain, A.; Sharma, R.K.; Jain, A.; Singh, B. Stimuli Responsive in Situ Gelling Systems Loaded with PLGA Nanoparticles of Moxifloxacin Hydrochloride for Effective Treatment of Periodontitis. AAPS PharmSciTech 2020, 21, 76. [CrossRef]

124. Xu, S.; Zhou, Q.; Jiang, Z.; Wang, Y.; Yang, K.; Qiu, X.; Ji, Q. The Effect of Doxycycline-Containing Chitosan/Carboxymethyl Chitosan Nanoparticles on NLRP3 Inflammasome in Periodontal Disease. Carbohydr. Polym. 2020, 237, 116163. [CrossRef]

125. Olsen, I.; Yilmaz, Ö. Modulation of Inflammasome Activity by Porphyromonas Gingivalis in Periodontitis and Associated Systemic Diseases. J. Oral Microbiol. 2016, 8, 1-11. [CrossRef]

126. Martin, V.; Ribeiro, I.A.C.; Alves, M.M.; Gonçalves, L.; Almeida, A.J.; Grenho, L.; Fernandes, M.H.; Santos, C.F.; Gomes, P.S.; Bettencourt, A.F. Understanding Intracellular Trafficking and Anti-Inflammatory Effects of Minocycline Chitosan-Nanoparticles in Human Gingival Fibroblasts for Periodontal Disease Treatment. Int. J. Pharm. 2019, 572, 118821. [CrossRef]

127. Hu, F.; Zhou, Z.; Xu, Q.; Fan, C.; Wang, L.; Ren, H.; Xu, S.; Ji, Q.; Chen, X. A Novel PH-Responsive Quaternary Ammonium Chitosan-Liposome Nanoparticles for Periodontal Treatment. Int. J. Biol. Macromol. 2019, 129, 1113-1119. [CrossRef]

128. Echazú, M.; Olivetti, C.; Peralta, I.; Alonso, M.; Anesini, C.; Perez, C.; Alvarez, G.; Desimone, M. Development of PH-Responsive Biopolymer-Silica Composites Loaded with Larrea Divaricata Cav. Extract with Antioxidant Activity. Colloids Surf. B Biointerfaces 2018, 169, 82-91. [CrossRef]

129. Aminu, N.; Chan, S.Y.; Yam, M.F.; Toh, S.M. A Dual-Action Chitosan-Based Nanogel System of Triclosan and Flurbiprofen for Localised Treatment of Periodontitis. Int. J. Pharm. 2019, 570, 118659. [CrossRef] [PubMed]

130. Sims, K.R.; Sims, K.R.; He, B.; Koo, H.; Koo, H.; Benoit, D.S.W.; Benoit, D.S.W.; Benoit, D.S.W.; Benoit, D.S.W.; Benoit, D.S.W. Electrostatic Interactions Enable Nanoparticle Delivery of the Flavonoid Myricetin. ACS Omega 2020, 5, 12649-12659. [CrossRef] [PubMed]

131. Sims, K.R.; Maceren, J.P.; Liu, Y.; Rocha, G.R.; Koo, H.; Benoit, D.S.W. Dual Antibacterial Drug-Loaded Nanoparticles Synergistically Improve Treatment of Streptococcus Mutans Biofilms. Acta Biomater. 2020, 115, 418-431. [CrossRef] [PubMed]

132. Rostami Rad, M.; Pourhajibagher, M.; Reza Rokn, A.R.; Barikani, H.R.; Bahador, A. Effect of Antimicrobial Photodynamic Therapy Using Indocyanine Green Doped with Chitosan Nanoparticles on Biofilm Formation-Related Gene Expression of Aggregatibacter Actinomycetemcomitans. Front. Dent. 2019, 16, 187. [CrossRef]

133. Lecio, G.; Ribeiro, F.V.; Pimentel, S.P.; Reis, A.A.; da Silva, R.V.C.; Nociti-Jr, F.; Moura, L.; Duek, E.; Casati, M.; Casarin, R.C.V. Novel 20\% Doxycycline-Loaded PLGA Nanospheres as Adjunctive Therapy in Chronic Periodontitis in Type-2 Diabetics: Randomized Clinical, Immune and Microbiological Trial. Clin. Oral Investig. 2020, 24, 1269-1279. [CrossRef]

134. Makvandi, P.; Ghaemy, M.; Ghadiri, A.A.; Mohseni, M. Photocurable, Antimicrobial Quaternary Ammonium-Modified Nanosilica. J. Dent. Res. 2015, 94, 1401-1407. [CrossRef]

135. Kenawy, E.R.; Worley, S.D.; Broughton, R. The Chemistry and Applications of Antimicrobial Polymers: A State-of-the-Art Review. Biomacromolecules 2007, 8, 1359-1384. [CrossRef] [PubMed]

136. Alamri, A.; El-Newehy, M.H.; Al-Deyab, S.S. Biocidal Polymers: Synthesis and Antimicrobial Properties of Benzaldehyde Derivatives Immobilized onto Amine-Terminated Polyacrylonitrile. Chem. Cent. J. 2012, 6, 1-13. [CrossRef]

137. Xue, Y.; Xiao, H.; Zhang, Y. Antimicrobial Polymeric Materials with Quaternary Ammonium and Phosphonium Salts. Int. J. Mol. Sci. 2015, 16, 3626-3655. [CrossRef]

138. Huang, K.S.; Yang, C.H.; Huang, S.L.; Chen, C.Y.; Lu, Y.Y.; Lin, Y.S. Recent Advances in Antimicrobial Polymers: A Mini-Review. Int. J. Mol. Sci. 2016, 17, 1578. [CrossRef] 
139. Timofeeva, L.; Kleshcheva, N. Antimicrobial Polymers: Mechanism of Action, Factors of Activity, and Applications. Appl. Microbiol. Biotechnol. 2011, 89, 475-492. [CrossRef] [PubMed]

140. Álvarez-Paino, M.; Muñoz-Bonilla, A.; Fernández-García, M. Antimicrobial Polymers in the Nano-World. Nanomaterials 2017, 7, 48. [CrossRef] [PubMed]

141. Beyth, N.; Yudovin-Farber, I.; Bahir, R.; Domb, A.J.; Weiss, E.I. Antibacterial Activity of Dental Composites Containing Quaternary Ammonium Polyethylenimine Nanoparticles against Streptococcus Mutans. Biomaterials 2006, 27, 3995-4002. [CrossRef] [PubMed]

142. Chen, A.; Peng, H.; Blakey, I.; Whittaker, A.K. Biocidal Polymers: A Mechanistic Overview. Polym. Rev. 2017, 57, 276-310. [CrossRef]

143. Huang, Q.T.; He, J.W.; Lin, Z.M.; Liu, F.; Lassila, L.V.J.; Vallittu, P.K. Physical and Chemical Properties of an Antimicrobial Bis-GMA Free Dental Resin with Quaternary Ammonium Dimethacrylate Monomer. J. Mech. Behav. Biomed. Mater. 2016, 56, 68-76. [CrossRef]

144. Li, S.; Yu, X.; Liu, F.; Deng, F.; He, J. Synthesis of Antibacterial Dimethacrylate Derived from Niacin and Its Application in Preparing Antibacterial Dental Resin System. J. Mech. Behav. Biomed. Mater. 2020, 102, 103521. [CrossRef]

145. Silva, P.A.M.; Garcia, I.M.; Nunes, J.; Visioli, F.; Leitune, V.C.B.; Melo, M.A.; Collares, F.M. Myristyltrimethylammonium Bromide (MYTAB) as a Cationic Surface Agent to Inhibit Streptococcus Mutans Grown over Dental Resins: An in Vitro Study. J. Funct. Biomater. 2020, 11, 1-13.

146. Li, F.; Weir, M.D.; Fouad, A.F.; Xu, H.H. Effect of Salivary Pellicle on Antibacterial Activity of Novel Antibacterial Dental Adhesives Using a Dental Plaque Microcosm Biofilm Model. Dent. Mater. 2014, 30, 182-191. [CrossRef]

147. Chen, H.; Tang, Y.; Weir, M.D.; Gao, J.; Imazato, S.; Oates, T.W.; Lei, L.; Wang, S.; Hu, T.; Xu, H.H.K. Effects of S. Mutans Gene-Modification and Antibacterial Monomer Dimethylaminohexadecyl Methacrylate on Biofilm Growth and Acid Production. Dent. Mater. 2020, 36, 296-309. [CrossRef]

148. Zhang, N.; Chen, C.; Melo, M.A.; Bai, Y.X.; Cheng, L.; Xu, H.H. A Novel Protein-Repellent Dental Composite Containing 2-Methacryloyloxyethyl Phosphorylcholine. Int. J. Oral Sci. 2015, 7, 103-109. [CrossRef] [PubMed]

149. Kwon, J.S.; Kim, J.Y.; Mangal, U.; Seo, J.Y.; Lee, M.J.; Jin, J.; Yu, J.H.; Choi, S.H. Durable Oral Biofilm Resistance of 3d-Printed Dental Base Polymers Containing Zwitterionic Materials. Int. J. Mol. Sci. 2021, 22, 417. [CrossRef]

150. Yumoto, H.; Hirota, K.; Hirao, K.; Miyazaki, T.; Yamamoto, N.; Miyamoto, K.; Murakami, K.; Fujiwara, N.; Matsuo, T.; Miyake, Y. Anti-Inflammatory and Protective Effects of 2-Methacryloyloxyethyl Phosphorylcholine Polymer on Oral Epithelial Cells. J. Biomed. Mater. Res. Part A 2015, 103, 555-563. [CrossRef] [PubMed]

151. Fujiwara, N.; Yumoto, H.; Miyamoto, K.; Hirota, K.; Nakae, H.; Tanaka, S.; Murakami, K.; Kudo, Y.; Ozaki, K.; Miyake, Y. 2-Methacryloyloxyethyl Phosphorylcholine (MPC)-Polymer Suppresses an Increase of Oral Bacteria: A Single-Blind, Crossover Clinical Trial. Clin. Oral Investig. 2019, 23, 739-746. [CrossRef]

152. Park, S.Y.; Yoo, K.H.; Yoon, S.Y.; Son, W.S.; Kim, Y.I. Synergetic Effect of 2-methacryloyloxyethyl Phosphorylcholine and Mesoporous Bioactive Glass Nanoparticles on Antibacterial and Anti-demineralisation Properties in Orthodontic Bonding Agents. Nanomaterials 2020, 10, 1282. [CrossRef]

153. Jiang, S.; Cao, Z. Ultralow-Fouling, Functionalizable, and Hydrolyzable Zwitterionic Materials and Their Derivatives for Biological Applications. Adv. Mater. 2010, 22, 920-932. [CrossRef] [PubMed]

154. Chou, Y.N.; Venault, A.; Cho, C.H.; Sin, M.C.; Yeh, L.C.; Jhong, J.F.; Chinnathambi, A.; Chang, Y.; Chang, Y. Epoxylated Zwitterionic Triblock Copolymers Grafted onto Metallic Surfaces for General Biofouling Mitigation. Langmuir 2017, 33, 9822-9835. [CrossRef] [PubMed]

155. Hirota, K.; Murakami, K.; Nemoto, K.; Miyake, Y. Coating of a Surface with 2-Methacryloyloxyethyl Phosphorylcholine (MPC) Co-Polymer Significantly Reduces Retention of Human Pathogenic Microorganisms. FEMS Microbiol. Lett. 2005, 248, 37-45. [CrossRef]

156. Hirota, K.; Yumoto, H.; Miyamoto, K.; Yamamoto, N.; Murakami, K.; Hoshino, Y.; Matsuo, T.; Miyake, Y. MPC-Polymer Reduces Adherence and Biofilm Formation by Oral Bacteria. J. Dent. Res. 2011, 90, 900-905. [CrossRef] [PubMed]

157. Zhang, N.; Ma, J.; Melo, M.A.; Weir, M.D.; Bai, Y.; Xu, H.H. Protein-Repellent and Antibacterial Dental Composite to Inhibit Biofilms and Caries. J. Dent. 2015, 43, 225-234. [CrossRef] [PubMed]

158. Imazato, S.; Ebi, N.; Takahashi, Y.; Kaneko, T.; Ebisu, S.; Russell, R.R.B. Antibacterial Activity of Bactericide-Immobilized Filler for Resin-Based Restoratives. Biomaterials 2003, 24, 3605-3609. [CrossRef]

159. Kwon, J.S.; Lee, M.J.; Kim, J.Y.; Kim, D.; Ryu, J.H.; Jang, S.; Kim, K.M.; Hwang, C.J.; Choi, S.H. Novel Anti-Biofouling LightCurable Fluoride Varnish Containing 2-Methacryloyloxyethyl Phosphorylcholine to Prevent Enamel Demineralization. Sci. Rep. 2019, 9, 1-9. [CrossRef] [PubMed]

160. Wang, Y.; Fan, Y.; Zhou, Z.; Tu, H.; Ren, Q.; Wang, X.; Ding, L.; Zhou, X.; Zhang, L. De Novo Synthetic Short Antimicrobial Peptides against Cariogenic Bacteria. Arch. Oral Biol. 2017, 80, 41-50. [CrossRef]

161. Xie, X.; Wang, L.; Xing, D.; Zhang, K.; Weir, M.D.; Liu, H.; Bai, Y.; Xu, H.H.K. Novel Dental Adhesive with Triple Benefits of Calcium Phosphate Recharge, Protein-Repellent and Antibacterial Functions. Dent. Mater. 2017, 33, 553-563. [CrossRef]

162. Lee, M.J.; Kwon, J.S.; Kim, J.Y.; Ryu, J.H.; Seo, J.Y.; Jang, S.; Kim, K.M.; Hwang, C.J.; Choi, S.H. Bioactive Resin-Based Composite with Surface Pre-Reacted Glass-Ionomer Filler and Zwitterionic Material to Prevent the Formation of Multi-Species Biofilm. Dent. Mater. 2019, 35, 1331-1341. [CrossRef] [PubMed] 
163. Koyama, J.; Fukazawa, K.; Ishihara, K.; Mori, Y. In Situ Surface Modification on Dental Composite Resin Using 2Methacryloyloxyethyl Phosphorylcholine Polymer for Controlling Plaque Formation. Mater. Sci. Eng. C 2019, 104, 109916. [CrossRef] [PubMed]

164. Kwon, J.S.; Lee, M.J.; Kim, J.Y.; Kim, D.; Ryu, J.H.; Jang, S.; Kim, K.M.; Hwang, C.J.; Choi, S.H. Novel Anti-Biofouling Bioactive Calcium Silicate-Based Cement Containing 2-Methacryloyloxyethyl Phosphorylcholine. PLoS ONE 2019, 14, e0211007. [CrossRef] [PubMed]

165. Ikeya, K.; Iwasa, F.; Inoue, Y.; Fukunishi, M.; Takahashi, N.; Ishihara, K.; Baba, K. Inhibition of Denture Plaque Deposition on Complete Dentures by 2-Methacryloyloxyethyl Phosphorylcholine Polymer Coating: A Clinical Study. J. Prosthet. Dent. 2018, 119, 67-74. [CrossRef]

166. Tincho, M.B.; Morris, T.; Meyer, M.; Pretorius, A. Antibacterial Activity of Rationally Designed Antimicrobial Peptides. Int. J. Microbiol. 2020, 2020, 2131535. [CrossRef] [PubMed]

167. Huang, Z.B.; Shi, X.; Mao, J.; Gong, S.Q. Design of a Hydroxyapatite-Binding Antimicrobial Peptide with Improved Retention and Antibacterial Efficacy for Oral Pathogen Control. Sci. Rep. 2016, 6, 1-11. [CrossRef]

168. Greenhalgh, R.; Dempsey-Hibbert, N.C.; Whitehead, K.A. Antimicrobial Strategies to Reduce Polymer Biomaterial Infections and Their Economic Implications and Considerations. Int. Biodeterior. Biodegrad. 2019, 136, 1-14. [CrossRef]

169. Niu, J.Y.; Yin, I.X.; Wu, W.K.K.; Li, Q.L.; Mei, M.L.; Chu, C.H. Antimicrobial Peptides for the Prevention and Treatment of Dental Caries: A Concise Review. Arch. Oral Biol. 2021, 122, 105022. [CrossRef] [PubMed]

170. Tu, H.; Fan, Y.; Lv, X.; Han, S.; Zhou, X.; Zhang, L. Activity of Synthetic Antimicrobial Peptide GH12 against Oral Streptococci. Caries Res. 2016, 50, 48-61. [CrossRef] [PubMed]

171. Jiang, W.; Wang, Y.; Luo, J.; Li, X.; Zhou, X.; Li, W.; Zhang, L. Effects of Antimicrobial Peptide GH12 on the Cariogenic Properties and Composition of a Cariogenic Multispecies Biofilm. Appl. Environ. Microbiol. 2018, 84, 1-13. [CrossRef] [PubMed]

172. Wang, Y.; Zeng, Y.; Wang, Y.; Li, H.; Yu, S.; Jiang, W.; Li, Y.; Zhang, L. Antimicrobial Peptide GH12 Targets Streptococcus Mutans to Arrest Caries Development in Rats. J. Oral Microbiol. 2019, 11, 1549921. [CrossRef]

173. Jiang, W.; Luo, J.; Wang, Y.; Chen, X.; Jiang, X.; Feng, Z.; Zhang, L. The PH-Responsive Property of Antimicrobial Peptide GH12 Enhances Its Anticaries Effects at Acidic PH. Caries Res. 2021, 55, 21-31. [CrossRef] [PubMed]

174. Chen, L.; Jia, L.; Zhang, Q.; Zhou, X.; Liu, Z.; Li, B.; Zhu, Z.; Wang, F.; Yu, C.; Zhang, Q.; et al. A Novel Antimicrobial Peptide against Dental-Caries-Associated Bacteria. Anaerobe 2017, 47, 165-172. [CrossRef]

175. Min, K.R.; Galvis, A.; Williams, B.; Rayala, R.; Cudic, P.; Ajdic, D. Antibacterial and Antibiofilm Activities of a Novel Synthetic Cyclic Lipopeptide against Cariogenic Streptococcus Mutans UA159. Antimicrob. Agents Chemother. 2017, 61, 1-14. [CrossRef]

176. Wang, X.; Wang, Y.; Wang, K.; Ren, Q.; Li, H.; Zheng, S.; Niu, Y.; Zhou, X.; Li, W.; Zhang, L. Bifunctional Anticaries Peptides with Antibacterial and Remineralizing Effects. Oral Dis. 2019, 25, 488-496. [CrossRef]

177. Wang, H.Y.; Cheng, J.W.; Yu, H.Y.; Lin, L.; Chih, Y.H.; Pan, Y.P. Efficacy of a Novel Antimicrobial Peptide Against Periodontal Pathogens in Both Planktonic and Polymicrobial Biofilm States. Acta Biomater. 2015, 25, 150-161. [CrossRef] [PubMed]

178. Bernegossi, J.; Calixto, G.M.F.; Da Silva Sanches, P.R.; Fontana, C.R.; Cilli, E.M.; Garrido, S.S.; Chorilli, M. Peptide KSL-W-Loaded Mucoadhesive Liquid Crystalline Vehicle as an Alternative Treatment for Multispecies Oral Biofilm. Molecules 2016, 21, 37. [CrossRef]

179. Zhang, L.Y.; Fang, Z.H.; Li, Q.L.; Cao, C.Y. A Tooth-Binding Antimicrobial Peptide to Prevent the Formation of Dental Biofilm. J. Mater. Sci. Mater. Med. 2019, 30, 45. [CrossRef] [PubMed]

180. Zhou, L.; Wong, H.M.; Zhang, Y.Y.; Li, Q.L. Constructing an Antibiofouling and Mineralizing Bioactive Tooth Surface to Protect against Decay and Promote Self-Healing. ACS Appl. Mater. Interfaces 2020, 12, 3021-3031. [CrossRef] [PubMed]

181. Calixto, G.M.F.; Garcia, M.H.; Cilli, E.M.; Chiavacci, L.A.; Chorilli, M. Design and Characterization of a Novel P1025 PeptideLoaded Liquid Crystalline System for the Treatment of Dental Caries. Molecules 2016, 21, 158. [CrossRef] [PubMed]

182. Aida, K.L.; Kreling, P.F.; Caiaffa, K.S.; Calixto, G.M.F.; Chorilli, M.; Spolidorio, D.M.P.; Santos-Filho, N.A.; Cilli, E.M.; Duque, C. Antimicrobial Peptide-Loaded Liquid Crystalline Precursor Bioadhesive System for the Prevention of Dental Caries. Int. J. Nanomed. 2018, 13, 3081-3091. [CrossRef] [PubMed]

183. Kirkwood, B.; Miller, M.; Milleman, J.; Milleman, K.; Leung, K. Four-Day Plaque Regrowth Evaluation of a Peptide Chewing Gum in a Double-Blind Randomized Clinical Trial. Clin. Exp. Dent. Res. 2020, 6, 318-327. [CrossRef] [PubMed]

184. Wang, H.; Ai, L.; Zhang, Y.; Cheng, J.; Yu, H.; Li, C.; Zhang, D.; Pan, Y.; Lin, L. The Effects of Antimicrobial Peptide Nal-P-113 on Inhibiting Periodontal Pathogens and Improving Periodontal Status. Biomed. Res. Int. 2018, 2018, 1805793. [CrossRef]

185. Xie, S.-X.; Song, L.; Yuca, E.; Boone, K.; Sarikaya, R.; VanOosten, S.K.; Misra, A.; Ye, Q.; Spencer, P.; Tamerler, C. Antimicrobial Peptide-Polymer Conjugates for Dentistry. ACS Appl. Polym. Mater. 2020, 2, 1134-1144. [CrossRef]

186. Wisdom, E.C.; Zhou, Y.; Chen, C.; Tamerler, C.; Snead, M.L. Mitigation of Peri-Implantitis by Rational Design of Bifunctional Peptides with Antimicrobial Properties. ACS Biomater. Sci. Eng. 2020, 6, 2682-2695. [CrossRef]

187. Su, M.; Yao, S.; Gu, L.; Huang, Z.; Mai, S. Antibacterial Effect and Bond Strength of a Modified Dental Adhesive Containing the Peptide Nisin. Peptides 2018, 99, 189-194. [CrossRef]

188. Shin, J.M.; Ateia, I.; Paulus, J.R.; Liu, H.; Fenno, J.C.; Rickard, A.H.; Kapila, Y.L. Antimicrobial Nisin Acts against Saliva Derived Multi-Species Biofilms without Cytotoxicity to Human Oral Cells. Front. Microbiol. 2015, 6, 1-14. [CrossRef] 
189. Hagiwara, A.; Imai, N.; Nakashima, H.; Toda, Y.; Kawabe, M.; Furukawa, F.; Delves-Broughton, J.; Yasuhara, K.; Hayashi, S.M. A 90-Day Oral Toxicity Study of Nisin A, an Anti-Microbial Peptide Derived from Lactococcus Lactis Subsp. Lactis, in F344 Rats. Food Chem. Toxicol. 2010, 48, 2421-2428. [CrossRef] [PubMed]

190. Xie, S.X.; Boone, K.; VanOosten, S.K.; Yuca, E.; Song, L.; Ge, X.; Ye, Q.; Spencer, P.; Tamerler, C. Peptide Mediated Antimicrobial Dental Adhesive System. Appl. Sci. 2019, 9, 557. [CrossRef] [PubMed]

191. Moussa, D.G.; Kirihara, J.A.; Ye, Z.; Fischer, N.G.; Khot, J.; Witthuhn, B.A.; Aparicio, C. Dentin Priming with Amphipathic Antimicrobial Peptides. J. Dent. Res. 2019, 98, 1112-1121. [CrossRef]

192. Moussa, D.G.; Fok, A.; Aparicio, C. Hydrophobic and Antimicrobial Dentin: A Peptide-Based 2-Tier Protective System for Dental Resin Composite Restorations. Acta Biomater. 2019, 88, 251-265. [CrossRef] [PubMed]

193. Mateescu, M.; Baixe, S.; Garnier, T.; Jierry, L.; Ball, V.; Haikel, Y.; Metz-Boutigue, M.H.; Nardin, M.; Schaaf, P.; Etienne, O.; et al. Antibacterial Peptide-Based Gel for Prevention of Medical Implanted-Device Infection. PLoS ONE 2015, 10, e0145143. [CrossRef]

194. Yazici, H.; O’Neill, M.B.; Kacar, T.; Wilson, B.R.; Oren, E.E.; Sarikaya, M.; Tamerler, C. Engineered Chimeric Peptides as Antimicrobial Surface Coating Agents toward Infection-Free Implants. ACS Appl. Mater. Interfaces 2016, 8, 5070-5081. [CrossRef] [PubMed]

195. Kuroda, K.; Caputo, G.A. Antimicrobial polymers as synthetic mimics of host-defense peptides. Wiley Interdiscip. Rev. Nanomed. Nanobiotechnol. 2013, 5, 49-66. [CrossRef]

196. Mankoci, S.; Kaiser, R.L.; Sahai, N.; Barton, H.A.; Joy, A. Bactericidal peptidomimetic polyurethanes with remarkable selectivity against Escherichia coli. ACS Biomater. Sci. Eng. 2017, 3, 2588-2597. [CrossRef] [PubMed]

197. Pranantyo, D.; Xu, L.Q.; Kang, E.T.; Mya, M.K.; Chan-Park, M.B. Conjugation of polyphosphoester and antimicrobial peptide for enhanced bactericidal activity and biocompatibility. Biomacromolecules 2016, 17, 4037-4044. [CrossRef] [PubMed]

198. Zhou, C.; Yuan, Y.; Zhou, P.; Wang, F.; Hong, Y.; Wang, N.; Xu, S.; Du, J. Highly effective antibacterial vesicles based on peptide-mimetic alternating copolymers for bone repair. Biomacromolecules 2017, 18, 4154-4162. [CrossRef]

199. Takahashi, H.; Nadres, E.T.; Kuroda, K. Cationic amphiphilic polymers with antimicrobial activity for oral care applications: Eradication of S. mutans biofilm. Biomacromolecules 2017, 18, 257-265. [CrossRef]

200. Gao, Q.; Li, P.; Zhao, H.; Chen, Y.; Jiang, L.; Ma, P.X. Methacrylate-ended polypeptides and polypeptoids for antimicrobial and antifouling coatings. Polym. Chem. 2017, 8, 6386-6397. [CrossRef]

201. Lam, S.J.; Wong, E.H.; O’Brien-Simpson, N.M.; Pantarat, N.; Blencowe, A.; Reynolds, E.C.; Qiao, G.G. Bionano interaction study on antimicrobial star-shaped peptide polymer nanoparticles. ACS Appl. Mater. Interfaces 2016, 8, 33446-33456. [CrossRef] [PubMed]

202. Cieplik, F.; Jakubovics, N.S.; Buchalla, W.; Maisch, T.; Hellwig, E.; Al-Ahmad, A. Resistance toward chlorhexidine in oral bacteria-is there cause for concern? Front. Microbiol. 2019, 10, 587. [CrossRef]

203. Do Amaral, G.S.; Negrini, T.; Maltz, M.; Arthur, R.A. Restorative Materials Containing Antimicrobial Agents: Is There Evidence for Their Antimicrobial and Anticaries Effects? A Systematic Review. Aust. Dent. J. 2016, 61, 6-15. [CrossRef]

204. Guo, L.; Edlund, A. Targeted antimicrobial peptides: A novel technology to eradicate harmful Streptococcus Mutans. J. Calif. Dent. Assoc. 2017, 45, 557-564. [PubMed]

205. Garcia, S.S.; Blackledge, M.S.; Michalek, S.; Su, L.; Ptacek, T.; Eipers, P.; Morrow, C.; Lefkowitz, E.J.; Melander, C.; Wu, H. Targeting of Streptococcus mutans biofilms by a novel small molecule prevents dental caries and preserves the oral microbiome. J. Dent. Res. 2017, 96, 807-814. [CrossRef] 